\title{
Phytopathology
}

\section{Fusarium verticillioides: Advancements in Understanding the Toxicity, Virulence, and Niche Adaptations of a Model Mycotoxigenic Pathogen of Maize}

\author{
Alex A. Blacutt, Scott E. Gold, Kenneth A. Voss, Minglu Gao, and Anthony E. Glenn ${ }^{\dagger}$
}

First and fourth authors: Department of Plant Pathology, University of Georgia, Athens 30602; and second, third, and fifth authors: United States Department of Agriculture-Agricultural Research Service, U.S. National Poultry Research Center, Toxicology and Mycotoxin Research Unit, Athens, GA 30605-2720.

Accepted for publication 29 September 2017.

\begin{abstract}
The importance of understanding the biology of the mycotoxigenic fungus Fusarium verticillioides and its various microbial and plant host interactions is critical given its threat to maize, one of the world's most valuable food crops. Disease outbreaks and mycotoxin contamination of grain threaten economic returns and have grave implications for human and animal health and food security. Furthermore, $F$. verticillioides is a member of a genus of significant phytopathogens and, thus, data regarding its host association, biosynthesis of secondary metabolites, and other metabolic (degradative) capabilities are consequential to both basic and applied research efforts across multiple pathosystems. Notorious among its secondary metabolites are the fumonisin mycotoxins, which cause severe animal diseases and are implicated in human disease. Additionally, studies of these mycotoxins have led to new understandings of $F$. verticillioides plant pathogenicity and provide tools for research into cellular processes and host-pathogen interaction strategies. This review presents current knowledge regarding several significant lines of $F$. verticillioides research, including facets of toxin production, virulence, and novel fitness strategies exhibited by this fungus across rhizosphere and plant environments.
\end{abstract}

Mycotoxins are toxic fungal secondary metabolites that can accumulate in food and feed, causing harm to animals and, potentially, humans. Although many crops are prone to infection by mycotoxigenic fungi, cereals are of particular concern due to their frequently high levels of mycotoxin contamination and their common use in raw or processed foods. Information regarding the risks of mycotoxin contamination dates back to at least 600 B.C.E., where ergot was likely the subject referred to as a "noxious pustule in the ear of grain" on an Assyrian tablet (Bennett and Klich 2003). Although mycotoxin impacts on human and animal health likely date back millennia, they only became the subject of intense study after a 1960 epidemic affecting English turkey production. Called "turkey X disease," this epidemic claimed over 100,000 turkey poults and other fowl due to consumption of moldy peanut meal, later discovered to be contaminated with high aflatoxin concentrations (Kensler et al. 2011).

Fungi in the genera Aspergillus, Fusarium, and Penicillium produce the mycotoxins of greatest importance to animal and human health. Particularly noteworthy are the aflatoxins, fumonisins, ochratoxin A,

${ }^{\dagger}$ Corresponding author: A. E. Glenn; E-mail: anthony.glenn@ars.usda.gov

This article is in the public domain and not copyrightable. It may be freely reprinted with customary crediting of the source. The American Phytopathological Society, 2018. trichothecenes, and zearalenone (Bennett and Klich 2003). Mycotoxins are generally considered of minimal human health significance in the developed world, where dependence on a single staple is low and infrastructure exists to prevent and detect significant contamination. However, in developing nations and communities dependent on subsistence agriculture, humans are often reliant on one or a few main staple crops. The increased consumption of individual susceptible crops increases exposure of these populations to mycotoxins. Often, in such circumstances, storage conditions and mycotoxin monitoring infrastructure are inadequate to prevent highly contaminated grain from reaching consumers.

One of the major sources of mycotoxin exposure for humans in Latin America and in Africa is contaminated maize grain. Dramatic episodes of aflatoxin contamination in Kenya have led to acute aflatoxicoses resulting in fatalities (Diallo et al. 1995; Probst et al. 2007). Hepatic carcinoma is associated with chronic exposure to aflatoxins, and increased susceptibility to the cancer is correlated with hepatitis B virus infections, which are unfortunately present at high rates (exceeding $8 \%$ in portions of sub-Saharan Africa) in many of the same areas affected by high aflatoxin exposure (Diallo et al. 1995). Maize is also frequently contaminated with fumonisin mycotoxins. The fumonisins, primarily produced by Fusarium verticillioides (previously $F$. moniliforme, from which the toxin name is derived), frequently cocontaminate aflatoxin-containing grain. 
This review encapsulates the wealth of research on $F$. verticillioides as a plant pathogen but also outlines the general concern this fungus presents to human and animal health due to its production of fumonisin mycotoxins. We begin with a brief historical recounting of significant discoveries elucidating $F$. verticillioides mycotoxigenicity and the role of fumonisins. The focus then shifts to various aspects of F. verticillioides as a plant pathogen and its interactions with maize, including mechanisms underlying pathogenicity. Finally, we discuss research on niche adaptations and fitness factors that contribute to the competitive success of $F$. verticillioides as both an endophyte and pathogen of maize worldwide. The overall biology, characteristics, and resources available for both $F$. verticillioides and maize collectively make the two a model pathosystem for identifying, evaluating, and thoroughly characterizing the molecular, biochemical, physiological, and ecological facets of both the plant-fungus association and their interactions with the cohort microbial community.

\section{HISTORY OF FUMONISIN MYCOTOXICOSIS IN HUMANS AND ANIMALS AND THE MECHANISM OF TOXICITY}

Historical events leading to the discovery of the fumonisin mycotoxins have been reviewed in detail by Marasas (2001), and we only highlight here some of the key points. Fumonisins are known to cause dramatic disease, including fatalities, in porcine and equine species. In fact, fumonisins were identified after an association was made between consumption of moldy maize and a debilitating syndrome in horses known as equine leukoencephalomalacia (ELEM) in the 1970s and 1980s. ELEM is characterized by liquefactive-hemorrhagic lesions found predominantly in the white matter of the horse cerebrum. The identification of $F$. verticillioides as the fungus involved in an ELEM outbreak in South Africa was a major breakthrough for understanding and managing the syndrome (Kellerman et al. 1972; Marasas et al. 1976). Intense investigation of the toxic and carcinogenic effects of $F$. verticillioides using fungal culture materials confirmed that the fungus also causes liver toxicity in rats and other species, as well as pulmonary edema in pigs (Kriek et al. 1981a). Feeding trials in rats also demonstrated the hepatocarcinogenicity of $F$. verticillioides culture material (Kriek et al. 1981b; Marasas et al. 1984). Later, maize naturally contaminated with $F$. verticillioides was involved in an ELEM outbreak in the United States, and it was determined that the contaminated maize also caused the induction of proliferative hepatocyte lesions and bile duct tumors when fed to rats (Wilson et al. 1985). The prevalence of the fungus in maize was also found to correlate with esophageal cancer rates found in communities in southern Africa (Marasas 2001).

Induction of liver lesions and liver tumor promotion by $F$. verticillioides in rats formed the basis for a bioassay-driven approach that was simultaneously undertaken in several laboratories, resulting in the discovery and structural characterization of fumonisins $\mathrm{B}_{1}$ and $\mathrm{B}_{2}\left(\mathrm{FB}_{1}\right.$ and $\left.\mathrm{FB}_{2}\right)($ Gelderblom et al. 1988). The chemical structure of "macrofusin" (= fumonisin $\mathrm{B}_{1}$ ), a rat hepatotoxin isolated from fungal culture material, was published shortly thereafter (Laurent et al. 1989 , 1990). Following these reports, $\mathrm{FB}_{1}$ was confirmed to cause ELEM and pulmonary edema in pigs (Harrison et al. 1990; Kellerman et al. 1990). Furthermore, the nephrotoxicity of $\mathrm{FB}_{1}$ in rats and its hepatotoxicity in mice was established in feeding trials using maize naturally contaminated with fumonisins and culture-derived purified FB $_{1}$ (Voss et al. 1989, 1993, 1995). Gelderblom et al. (1991) first reported the liver carcinogenicity of $\mathrm{FB}_{1}$ after feeding diets containing the purified mycotoxin at $50 \mathrm{ppm}$ to rats. Later, researchers conducting feeding studies under the auspices of the U.S. National Toxicology Program observed that dietary concentrations of $\mathrm{FB}_{1}$ at $\geq 50$ ppm caused kidney carcinomas and adenomas in male rats and liver adenomas and carcinomas in female mice (Howard et al. 2001).

The $\mathrm{B}$ series fumonisins $\left(\mathrm{FB}_{1}, \mathrm{FB}_{2}, \mathrm{FB}_{3}\right.$, and $\left.\mathrm{FB}_{4}\right)$ are the most commonly studied due to their frequency of occurrence and the often high concentrations detected in maize infected with $F$. verticillioides.
A- and C-series fumonisins have been identified and differ from the B series by amine acetylation and lack of a $\mathrm{C}-1$ terminal methyl group, respectively (Proctor et al. 2008; Tamura et al. 2015). As the most abundant fumonisin produced by typical isolates of $F$. verticillioides, $\mathrm{FB}_{1}$ is the most thoroughly characterized fumonisin of more than 50 identified congeners and reaction products (Månsson et al. 2010), yet it is important to note that the toxicological importance of most of the other fumonisins remains unknown. It is also important to note that fumonisins are mostly stable under commonly used cooking and baking conditions; however, other preparation and cooking processes can cause acylation of the primary amino group of $\mathrm{FB}_{1}$ or the removal of the tricarballylic moieties by alkaline hydrolysis, as occurs during nixtamalization, which significantly reduces the toxicity (FernándezSurumay et al. 2005; Liu et al. 2001; Voss et al. 2009, 2011, 2013).

Fumonisin is a structural analog of sphinganine, which is a precursor molecule used for the biosynthesis of ceramide, and the $\mathrm{FB}_{1}$ mechanism of action conferring cellular toxicity is that it competitively inhibits the enzyme ceramide synthase (Riley et al. 2001; Wang et al. 1991). The consequences of inhibition include accumulation of the following in tissues: (i) sphinganine from the de novo ceramide biosynthetic pathway, (ii) sphingosine recycled from ceramide, and (iii) sphinganine 1-phosphate and sphingosine 1-phosphate due to kinase phosphorylation of the two respective sphingoid bases. Furthermore, inhibition of ceramide synthase results in reduction of complex sphingolipids derived from ceramide. The end result is an overall disruption of sphingolipid-dependent signaling and physiological functions. Ceramide synthase inhibition following fumonisin exposure occurs in all mammalian, avian, and piscine species tested to date and, interestingly, also in plants such as maize (Abbas et al. 1994; Williams et al. 2007; Zitomer et al. 2010). Ceramide synthase inhibition and altered sphingolipid profiles in tissues have been repeatedly shown to precede the onset of demonstrable toxicity in animals. That is, altered sphingolipid metabolism occurs at earlier times or at lower doses than the onset of toxicity, and the degree of sphingolipid metabolism disruption and the severity of toxicological effects are positively correlated (Bulder et al. 2012). Other events have also been mechanistically implicated as contributors to or modifiers of toxicity, including altered membrane lipid composition, TNF- $\alpha$ and other cyclins, nitric oxide, and disrupted folate utilization (Gelderblom et al. 2001; Voss et al. 2007).

Fumonisins have worldwide distribution in maize and maize-based foods and are occasionally found in other commodities (Bulder et al. 2012). The human health consequences of fumonisins are not established, although epidemiological evidence does implicate $F$. verticillioides and fumonisins as risk factors for cancer (e.g., esophageal) and neural tube birth defects in areas where contaminated maize is a dietary staple (Bulder et al. 2012; Gelineau-van Waes et al. 2009; Jaskiewicz et al. 1987; Marasas 2001). Food prepared from such maize provides a source for continuous exposure to fumonisins, which may also contribute to stunting in children (Shirima et al. 2015). Addressing these potential concerns, the International Agency for Research on Cancer summarized data estimating the fumonisin daily intake from several countries or regions in Africa and Latin America. They noted that the estimated daily intakes in some rural communities can exceed the provisional maximum tolerated daily intake level of $2 \mu \mathrm{g} / \mathrm{kg}$ of body weight established by the Food and Agriculture Organization-World Health Organization Joint Expert Committee on Food Additives (Bulder et al. 2012; Ostry et al. 2017). Furthermore, biomarker-based studies conducted in various communities in Guatemala revealed a positive correlation between amount of $\mathrm{FB}_{1}$ consumed (determined by urinary $\mathrm{FB}_{1}$ concentrations) and disruption of ceramide synthase activity based on elevated ratios of sphinganine 1-phosphate to sphingosine 1-phosphate in whole blood (Riley et al. 2015). Thus, humans are clearly exposed to fumonisins in communities where contaminated maize is a dietary staple, and altered sphingolipid metabolism is evident in those individuals having high daily intake of fumonisins. Additional investigation is needed to better understand 
how fumonisins might affect human health and how exposure can be minimized.

\section{F. VERTICILLIOIDES, A MODEL MAIZE PATHOGEN}

General features. Overall, $F$. verticillioides is very amenable and informative for studying molecular genetics of fungal physiology, fitness factors, general host interactions, and plant disease development. In laboratory settings, $F$. verticillioides is easily cultured on agar media and is readily transformable, with mutation studies benefitting from transformation options, including protoplast generation (Ramamoorthy et al. 2015), lithium acetate-treated conidia (Bourett et al. 2002), or Agrobacterium-mediated (Visentin et al. 2012) protocols. The species has a rapid growth rate in solid or liquid culture, and sexual crosses for generating meiotic progeny greatly facilitate genetic studies (Leslie and Summerell 2006). Both forward and reverse genetics in $F$. verticillioides are enhanced by a sequenced genome, annotated with the aid of extensive expressedsequence tags and other transcriptional data, with online databases providing valuable publicly available platforms for analysis (Brown et al. 2005; Grigoriev et al. 2012; Stajich et al. 2012). As a pathogen, $F$. verticillioides represents a serious economic threat to maize production and quality, and thorough experimental characterization carries significant public health and economic incentives. From a biotechnology perspective, unique and efficacious degradative enzymes that contribute to the success of $F$. verticillioides as a pathogen also have potential economic value for their utility in biofuel production (Ravalason et al. 2012). Maize itself is ubiquitous and easily cultivable, facilitating growth-chamber and greenhouse studies aimed at better understanding the intricacies of the pathosystem, although experiments requiring mature plants are generally more effectively performed in the field. Beyond $F$. verticillioides, the genus Fusarium encompasses numerous agriculturally significant pathogens, thus expanding the value of F. verticillioides experimental data across multiple species (Leslie and Summerell 2006).

Evolutionary origin of $\boldsymbol{F}$. verticillioides and its nuclear genome. Intimate host associations, such as the $F$. verticillioidesmaize system, present constant evolutionary pressure on both pathogen and host. Additionally, maize, like all domesticated crops, has undergone significant artificial selection, with an estimated $10 \%$ of the ancestral teosinte population contributing to maize genetic diversity across two "bottleneck" events (Wright et al. 2005). Single-nucleotide polymorphism analysis predicts approximately 1,200 positively selected genes responsible for morphological and biochemical characteristics of maize. It is reasonable to suspect that a pathogen having an intimate host association, such as $F$. verticillioides establishes with maize, must respond in kind to the evolving features of its host. Therefore, identifying and investigating the corresponding genetic adaptations in the fungus may result in development of new or improved strategies for managing plant disease and minimizing mycotoxin contamination.

F. verticillioides is a member of the phylogenetically defined F. fujikuroi species complex (FFSC), a monophyletic group largely overlapping the historically recognized section Liseola. The FFSC includes a number of morphologically diverse species and is supported by multilocus analyses involving the genes encoding translation elongation factor $1-\alpha, \beta$ tubulin, and a number of other housekeeping and metabolic loci (O'Donnell et al. 2000). This species complex is divided into the American, Asian, and African clades, with $F$. verticillioides phylogenetically positioned within the African clade. Given the strong host association that $F$. verticillioides has with maize and its teosinte ancestor, this species likely originated in Central America from an African progenitor. Another possibility is that $F$. verticillioides established its preference for maize after the plant was introduced to the African continent in the 16th century, and from there the pair were globally dispersed (De Vos et al. 2014; Kvas et al. 2009; Proctor et al. 2013). Regardless of the precise geographical origin of the species, $F$. verticillioides evolved after the divergence of the African and Asian clades of the FFSC approximately 7.3 million years ago (O'Donnell et al. 2013).

The genome of $F$. verticillioides is approximately $42 \mathrm{Mbp}$, with an estimated 14,179 genes (Kistler et al. 2013). Genetic mapping of the $F$. verticillioides genome identified 11 chromosomes and 1 supernumerary chromosome (Xu et al. 1995). Presence of the 12th chromosome varies across strains of $F$. verticillioides and, as observed with $F$. fujikuroi, loss of this chromosome is not accompanied by any observed phenotypic changes (Wiemann et al. 2013; Xu et al. 1995). Chromosomal organization and overall genomic characteristics between $F$. fujikuroi and $F$. verticillioides were noted to be highly similar, with one notable distinction being a higher frequency of transposable elements in F. fujikuroi (2.2\%) compared with $F$. verticillioides $(0.47 \%)$ (Wiemann et al. 2013). Amplified fragment length polymorphism analyses did identify some distinctive genomic divergences between $F$. verticillioides and representatives of two other FFSC clades, the Asian clade F. fujikuroi and American clade $F$. circinatum (De Vos et al. 2014). For example, F. fujikuroi was found to have a loss of roughly $0.9 \mathrm{Mbp}$ in chromosome 4 compared with the corresponding $F$. verticillioides chromosome, and a reciprocal translocation event is postulated in $F$. verticillioides and $F$. fujikuroi between the distal ends of chromosomes 8 and 11 as compared with $F$. circinatum (De Vos et al. 2014). Rearrangement and deletion are hypothesized to explain the absence of the gibberellin biosynthetic cluster in $F$. verticillioides, based on synteny and its presence in F. fujikuroi (Bömke et al. 2008).

Looking beyond the FFSC, the genomes of $F$. verticillioides, $F$. graminearum, $F$. oxysporum, and $F$. solani all differ widely in size and organization (Kistler et al. 2013). F. graminearum is unique, with 4 four chromosomes, whereas $F$. verticillioides, $F$. oxysporum, and $F$. solani each have 11,15 , and 17 , respectively. Collectively, data support the hypothesis that genome rearrangements paired with host associations have been major drivers of Fusarium speciation. Furthermore, F. graminearum and $F$. verticillioides, unlike $F$. oxysporum and $F$. solani, possess an active repeat-induced point mutation (RIP) mechanism active during sexual development and meiosis (Pomraning et al. 2013). As noted above, F. verticillioides has a low frequency of transposable elements and associated repeat content, which are hallmarks of RIP activity. Roughly $1.76 \%$ of the F. verticillioides genome is repetitive sequence, as compared with 27 and $15 \%$ in F. oxysporum and F. solani, respectively (Kistler et al. 2013). Although RIP activity serves to inactivate transposable elements or other repetitive sequences, off-target activity is hypothesized to drive evolution of pathogenicity factors through sequence diversification.

The genome of $F$. verticillioides is thought to have undergone a two-speed evolution, wherein genes involved in pathogenicity undergo strong diversifying selection while genes involved in conserved functions such as mycotoxin biosynthesis are maintained under neutral or purifying selection (Sperschneider et al. 2015). Rapidly evolving genes, determined via statistical comparison among chromosomes, are found on chromosomes 2, 4, 6, 7, 8, and 10, with chromosome 2 containing the highest proportion of these genes. Based on Munich Information Center for Protein Sequences functional analysis, chromosome 10 is enriched for rapidly evolving genes encoding functions related to disease, virulence, and defense, while chromosome 11 is enriched for secondary metabolism, virulence, and pathogenicity factors. Additionally, $24.3 \%$ of a subset of genes likely involved in pathogenicity (based on protein motifs involved in host sensing and proximity to pathogen-associated genes) are under diversifying selection, as compared with the genome-wide mean of $2.1 \%$. Genes coding for transcription factors and secreted proteins were not determined to be under heavier diversifying selection than the mean, although this may be an artifact of limited available orthology. The fumonisin biosynthetic cluster, like other genes coding for proteins of conserved function, are apparently under purifying selection. 
An exploration of five Fusarium genomes and the diversity and distribution of secondary metabolite biosynthetic clusters suggests that horizontal gene transfer (HGT) occurs at a significant rate and can drive diversity. Genes coding for gibberellin, bikaverin, and fumonisin biosynthesis are all known to have been transferred to distantly related fungi (Proctor et al. 2013). Sequence analyses in plant-pathogenic Fusarium spp. suggest that past instances of crosskingdom HGT have introduced bacterial genes that contribute to virulence (Gardiner et al. 2012). Two such genes identified in F. pseudograminearum encoding a putative hydrolase (FPSE_11233) and homoserine kinase (FPSE_07765) have orthologs in F. verticillioides (FVEG_13062 and FVEG_10494, respectively). Moreover, there is evidence for transfer of loci containing genes responsible for detoxification of the maize phytoanticipin 2-benzoxazolinone (BOA) from Fusarium spp. to other maize-associated fungi (discussed below).

The mitochondrial genome. The mitochondrial genomes of Fusarium spp. carry significant diversity, with an analysis across the FFSC finding evidence for recombination and horizontal transfer (Fourie et al. 2013). A unique open reading frame (ORF) encoding a putative membrane-associated protein (AEJ7932.1) is found in mitochondrial genomes of $F$. verticillioides, $F$. fujikuroi, $F$. graminearum, $F$. solani, and $F$. circinatum. Codon usage in this ORF suggests a common ancestral origin via horizontal transfer, followed by mutationor recombination-driven diversification. Across Fusarium mitochondrial genomes, differences in size and sequence identity are attributable to introns, with exon-only alignments showing $>93 \%$ identity as opposed to a range from 29 to $70 \%$ for the overall genomes. Phylogenetic trees derived from concatenated FFSC mitochondrial genes yielded results contradictory to those of phylogenies based on nuclear genes, primarily regarding the ancestral status of the African clade. Interestingly, phylogenies based on single mitochondrial genes yielded varying results compared with each other and a concatenated set, indicative of selection bias or recombination events (Fourie et al. 2013). Although this diversity precludes their utility in phylogenetic analyses, disagreements between mitochondrial and nuclear phylogenies provide support for a hybridization-based origin to the FFSC. These data provide a foundation for further work exploring the dynamics of Fusarium mitochondrial genomes.

Genetic and biochemical features of secondary metabolite production. A key genomic feature of fungal secondary metabolite biosynthesis is that the genes encoding the various enzymes responsible for catalyzing the formation of the metabolite are generally clustered together, often along with genes encoding a regulatory transcription factor and a transporter for efflux of the metabolite. For example, fumonisin production is encoded by a cluster of 16 contiguous and coexpressed genes (Brown et al. 2012). Other mycotoxins produced by $F$. verticillioides include fusarin $\mathrm{C}$, fusaric acid, and moniliformin (Glenn 2007). The biosynthetic gene cluster for fusarin C consists of 9 coexpressed genes and the fusaric acid cluster consists of 12 coexpressed genes (Brown et al. 2012, 2015). The genes responsible for biosynthesis of moniliformin are currently unknown.

Fumonisin production in Fusarium spp., with the exception of select F. oxysporum strains, is restricted to the FFSC, where at least one species per phylogeographical clade (Africa, Asia, and America) is confirmed to produce B or C type fumonisins (Proctor et al. 2013). The genomic context surrounding the cluster was shown to differ between each of the clades. For example, the F. verticillioides, F. proliferatum, $F$. anthophilum, and $F$. oxysporum fumonisin clusters are each flanked by different genes, suggesting either independent acquisitions or postacquisition genome rearrangements. Sequence phylogeny of the cluster across the FFSC and $F$. oxysporum, as well as a lower rate of divergence, suggest that $F$. oxysporum acquired the pathway via horizontal gene transfer, likely from $F$. bulbicola or another FFSC member within the American clade.

Biosynthesis of fumonisin appears to be strongly regulated at the transcriptional level, through a number of pathways, although the extent of their overlap is unclear (Woloshuk and Shim 2013). The fumonisin cluster cis-acting transcription factor Fum21 (FVEG_14633; reannotated from FVEG_00315) is a $\mathrm{Zn}(\mathrm{III})_{2} \mathrm{Cys}_{6}$ transcription factor with alternative splice forms thought to play a role in regulating expression (Brown et al. 2007). Additionally, FvStuA (FVEG_02853) is an APSES transcription factor that positively regulates fumonisin production (M. Rath and S. E. Gold, unpublished data). Furthermore, the global secondary metabolism regulators Lae1 (FVEG_05214) and Sge1 (FVEG_09150) also control fumonisin production (Brown et al. 2014; Butchko et al. 2012). Deletants of Mads1 (FVEG_01965), a conserved transcription factor and apparent secondary metabolism regulator, exhibit reductions in both polyketide synthase gene transcription and $\mathrm{FB}_{1}$ production (Ortiz and Shim 2013). Deletion of individual genes encoding the velvet family of proteins, FvVe1 (FVEG_09521) and FvVelB (FVEG_01498), also reduced FB $_{1}$ production and, additionally, impaired morphological and virulence functions (Lan et al. 2014; Li et al. 2006). Recently, the gene FUG1 (FVEG_04008) was described in $F$. verticillioides and proposed to act as a transcriptional regulator integral to mycotoxin production and pathogenicity (Ridenour and Bluhm 2017).

Toxin production is also regulated by $\mathrm{pH}$ and nutrient availability, indicative of biosynthesis being coupled to colonization of the host. Amylopectin is a major constituent of maize starch, and both amylopectin and dextrin, an intermediate product of amylopectin hydrolysis, stimulate fumonisin production (Bluhm and Woloshuk 2005). An $\alpha$-amylase-deficient mutant created by disrupting the gene $A M Y 1$ (FVEG_12957) had impaired production of $\mathrm{FB}_{1}$ on starchy kernels (Bluhm and Woloshuk 2005). Later, as the colonized maize germ becomes more alkaline, fumonisin production is repressed (Shim et al. 2003). Picot et al. (2010) published a comprehensive summary of environmental factors affecting fumonisin production, including a summary of genes and their impacts on fumonisin biosynthesis. We expanded this information to include genes involved in virulence and development because regulation of fumonisin production influences disease induction and lifestyle determination in F. verticillioides (Table 1). As will be discussed below in more detail, fumonisin is a virulence factor affecting the growth and development of sensitive genotypes of maize (Glenn et al. 2008).

Signaling pathway components have also been identified as key regulators of secondary metabolism and pathogenicity in F. verticillioides. For example, the $F$. verticillioides adenylate cyclase gene, FAC1 (FVEG_01363), plays a role in virulence in stalk rot assays and, although mutants lacking the gene were not affected in fumonisin production, they did exhibit increased bikaverin production and tolerance to heat and oxidative stress (Choi and Xu 2010). Furthermore, this signaling pathway has adapted and diverged within $F$. graminearum and $F$. verticillioides to regulate functions such as species-specific secondary metabolite production and, in the case of $F$. verticillioides, xenobiotic tolerance and polyketide synthesis, indicative of nichedriven evolution (Guo et al. 2016). The mitogen-activated protein kinase (MAPK) signaling cascade also affects host interactions. Deletion mutants in the MAPK FvMk1 (FVEG_05063) were deficient in pathogenicity, conidiation, and toxin production (Zhang et al. 2011). Furthermore, a MAPK kinase kinase encoded by $F v B C K 1$ (FVEG_05000) is involved in colonization of both sugarcane and maize stalks, likely via regulation of oxidative stress response (Zhang et al. 2015). Similarly, deletants for FvSO (FVEG_08055), which is likely involved in protein-protein interactions within signaling networks, exhibit pleiotropic symptoms, including reduced stalk rot virulence and $\mathrm{FB}_{1}$ production (Guo et al. 2015).

The likely role for fumonisins in managing or at least affecting the continuum between endophyte and pathogen (see below) necessitates strict regulatory control by $F$. verticillioides at the transcriptional and epigenetic levels. Epigenetic analysis has shown that chromatin structure affects fumonisin biosynthesis because growth in the presence of the histone deacetylase inhibitor TSA led to significant increases in transcript abundance for the fumonisin biosynthetic genes FUM21 and FUM1 (FVEG_00316), with a 
lesser impact on FUM8 (FVEG_00319) (Visentin et al. 2012). Furthermore, histone acetylation was shown to increase under conditions conducive to fumonisin production, and an ectopically placed $F U M 1$ promoter driving the expression of GFP significantly outperformed the native locus in transcript accumulation, supporting the hypothesis that DNA or chromatin topography and histone acetylation act as an epigenetic layer of regulation for secondary metabolism in F. verticillioides (Visentin et al. 2012). FvSet1 (FVEG_07811), a histone methyltransferase, provides further evidence for epigenetic lifestyle regulation because deletants exhibit reduced aerial hyphae on maize ears, are unable to produce $\mathrm{FB}_{1}$, and are more susceptible to environmental stressors ( $\mathrm{Gu}$ et al. 2017).

The impact of fumonisin on plant disease. The role of fumonisins as a $F$. verticillioides virulence factor has been examined with regard to seedling blight, stalk rot, and ear rot, and the most conclusive association is that $\mathrm{FB}_{1}$ is phytotoxic to susceptible genotypes of maize and plays a significant role in development of seedling disease. Reduced seed emergence and decreased height of seedlings resulted from exposure to $\mathrm{FB}_{1}$, either alone or in combination with a nonproducing strain of $F$. verticillioides, but the disease severity was less than that observed when seedlings were inoculated with a strain producing $\mathrm{FB}_{1}$ (Desjardins et al. 1995; Williams et al. 2007; Zitomer et al. 2010). Interestingly, transformation-mediated introduction of the fumonisin biosynthetic gene cluster into a nonproducing, nonpathogenic isolate, NRRL 25059, conferred to the transformants both fumonisin production and pathogenicity on maize seedlings (Glenn et al. 2008). This isolate was identified as F. verticillioides at that time but is now recognized as F. musae (Van Hove et al. 2011). One of the defining characteristics of $F$. musae is that it does not produce fumonisins because of a novel deletion of the entire biosynthetic gene cluster. Thus, by transforming NRRL 25059 with the FUM cluster, fumonisin biosynthesis was in essence restored, along with pathogenicity toward maize seedlings. The degree to which fumonisins affect disease severity is strongly dependent on environmental conditions such as light intensity (Oren et al. 2003) and host genotype. For example, the seedling blight-resistant Tama Flint landrace contains a heritable form of $\mathrm{FB}_{1}$ insensitivity but this toxin tolerance appears to be separate from the mechanism of seedling blight resistance and can facilitate higher accumulation of fumonisins in maize (Desjardins et al. 2007). In contrast to seedling blight disease, fumonisins do not appear to be involved in ear rot development, because silk-channel applied conidia from strains incapable of producing fumonisins still produced ear rot with the same frequency and severity as the wild type (Desjardins and Plattner 2000).

The issue of accumulation of fumonisins within maize plant tissues was addressed by a series of studies focused on fumonisin translocation from roots to leaves. One set of reports found that root infection by $F$. verticillioides was necessary for $\mathrm{FB}_{1}$ to accumulate in seedling leaves but actual fungal colonization of the leaves was not required, suggesting that the toxin moves within the plant in advance of the fungus, perhaps via transpiration-mediated bulk flow (Baldwin et al. 2014; Zitomer et al. 2010). The authors also showed preferential uptake and accumulation of $\mathrm{FB}_{1}$ in roots and leaves compared with $\mathrm{FB}_{2}$ or $\mathrm{FB}_{3}$. They did not detect accumulation of $\mathrm{FB}_{1}$ in leaves of uninoculated seedlings when the plants were watered with an aqueous solution of $\mathrm{FB}_{1}$. In contrast, a separate study indicated that some $\mathrm{FB}_{1}$ could accumulate in maize seedling leaves of uninfected plants watered with a $\mathrm{FB}_{1}$ solution (Arias et al. 2016). They found that uninfected $\mathrm{FB}_{1}$-watered plants accumulated the toxin in aerial tissues more readily than those plants infected with $F$. verticillioides. The contrasting results between the studies may be reflective of dynamic responses of $\mathrm{FB}_{1}$ uptake and movement within maize tissues among differing maize genotypes.

Consistent with its mode of action in mammals, $\mathrm{FB}_{1}$ also inhibits ceramide synthase in maize, resulting in the accumulation of the long-chain sphingoid bases sphinganine and phytosphingosine and their phosphorylated forms (Arias et al. 2016; Williams et al. 2007;
Zitomer et al. 2010). Furthermore, differential accumulation of $\mathrm{FB}_{1}$ and the sphingoid bases between resistant and susceptible cultivars suggests that maize possesses multiple ceramide synthase isoforms with different substrate specificities that can result in activation of defense responses and localized cell death in order to limit spread of the pathogen (Arias et al. 2016). Possession of an $\mathrm{FB}_{1}$-insensitive isoform of ceramide synthase is feasible because tomato genotypes resistant to AAL toxin, a structural analog of $\mathrm{FB}_{1}$ produced by the tomato pathogen Alternaria arborescens, possess an alternative mechanism for ceramide synthesis that is insensitive to the effects

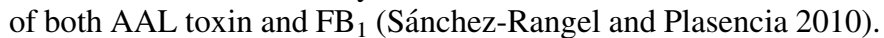

The $\boldsymbol{F}$. verticillioides-maize disease cycle. The multiple forms of plant disease caused by $F$. verticillioides are perhaps best described in the context of the life cycle of maize, its primary host. The Fusarium genus is home to facultative pathogens such as $F$. oxysporum and $F$. solani that are proficient soil inhabitants capable of saprophytic growth (Leslie and Summerell 2013). $F$. verticillioides has been observed to readily colonize soil but, as a species, it represents $10 \%$ or less of the total Fusarium soil community, suggesting that it is a capable colonizer but not an especially competitive one (Skoglund and Brown 1988). It is more frequently a colonizer of maize residue and was shown to persist for at least 630 days in both aboveground and buried ( $\leq 30 \mathrm{~cm}$ deep) stalks (Cotten and Munkvold 1998). The survival of $F$. verticillioides in buried samples declined in a linear fashion over the duration of the experiment but this pattern was less evident in surface samples that did not deteriorate as rapidly as the buried samples and were more likely to become recolonized by airborne conidia from other strains of the fungus. $F$. verticillioides was noted to colonize maize roots at a rate of $6 \times 10^{4}$ CFU/g (Pereira et al. 2007), thus showing the potential and relevance of soil and maize plant residue as a reservoir for inoculum. Indeed, Cotten and Munkvold (1998) stated that the long-term survival and recolonization of plant residue on the surface of soil may be as important for inoculum production as the long-term survival of the fungus itself.

Seed germinating in Fusarium-infested soils may develop an aggressive root rot and seedling blight (Fig. 1A) or they may acquire an asymptomatic, endophytic infection (Fig. 1B). The outcome is dependent on environmental conditions and a number of other factors. The $F$. verticillioides-Zea mays relationship does not happen in isolation, and maize-associated insects play a significant role in the disease cycle. The European corn borer and western corn rootworm are known to produce infection courts for Fusarium spp. through feeding on ears and stalks, respectively (Gilbertson et al. 1986; Munkvold et al. 1997; Sobek and Munkvold 1999). Under dry, presilk conditions, stalk wounds from mechanical damage or insect feeding become infection courts for $F$. verticillioides stalk rot (Fig. 1C), with successful infections providing both inoculum and attractants to insect pests that further spread the pathogen. In its adult stage, the European corn borer moth deposits its eggs on the abaxial surface of leaves, and the emerging larvae feed on leaf tissues and stalks before pupating, mating, and depositing a second generation of eggs across the plant tissues (Sobek and Munkvold 1999). The second-generation larvae feed on stalks, ears, and collar tissues, providing ample infection courts for development of F. verticillioides stalk and ear rots (Fig. 1C and E).

The process of seedling infection and disease development was characterized in detail using a green fluorescent protein (GFP)labeled strain of $F$. verticillioides (Oren et al. 2003). Under optimal growth conditions for the seedlings, initial hyphal growth of the fungus progressed sparsely along the root surface, with penetration of lateral roots and mesocotyl observed as early as $72 \mathrm{~h}$ after planting into infested soils, with subsequent invasive growth primarily intercellular in nature. Within 7 days, fungal growth had progressed but was limited to the mesocotyl tissue. Fourteen days into asymptomatic infection, growth into aerial tissues was sparse, with $F$. verticillioides undetectable by fluorescence microscopy but recoverable via plating plant tissues. At this point, the mesocotyl 
cells were observed to accumulate "undefined rounded organelles," and endophytic hyphae developed structures reminiscent of conidiophores. The mesocotyl cells containing the undefined structures were filled with conidia by 21 days after planting, and the surrounding cells were unaffected and disease symptoms were not observed at that time. By 30 days after planting, the fungal biomass had increased, causing necrosis of the mesocotyl and main root. Another study found that production of conidia may be essential for systemic movement of $F$. verticillioides within the plant because seed-inoculated aconidial strains were able to infect the mesocotyl but unable to infect the aerial parts of the plant (Baldwin et al. 2014). Rather than depending on intercellular hyphal growth for infection of the stem, movement of conidia through the vasculature may allow the fungus to more effectively traverse the developmentally complex first node that divides the mesocotyl from the aboveground coleoptile.

Under the disease-favorable condition of low light, $F$. verticillioides was noted to grow indiscriminately and aggressively throughout the roots, mesocotyl, and stem (Oren et al. 2003). This rapid growth and rot resulted in seedling mortality approximately 2 weeks after planting. The authors observed that the level of colonization and growth reduction correlated with the inoculum density in the soil, whereas seed inoculation was not inherently linked to disease, presumably due to lower inoculum levels. These results suggest that environmental conditions and inoculum density are strong determinants for the outcome of early maize $-F$. verticillioides interactions.

At the silking stage (Fig. 1D), thorough characterization using microscopy and histology indicated that the fungus colonizes developing kernels via a narrow opening called the stylar canal, giving rise to the commonly observed "starburst" pattern (Duncan and Howard 2010). If the diameter of the stylar canal opening is minimal, it can function as a physical barrier and is at least partially responsible for some resistant phenotypes. Environmental conditions also influence development of Fusarium ear rot. For example, wet postsilking conditions are conducive to ear rot, and drought stress in the form of warm, dry conditions during grain filling positively correlates with disease severity and fumonisin contamination (Munkvold 2003a).

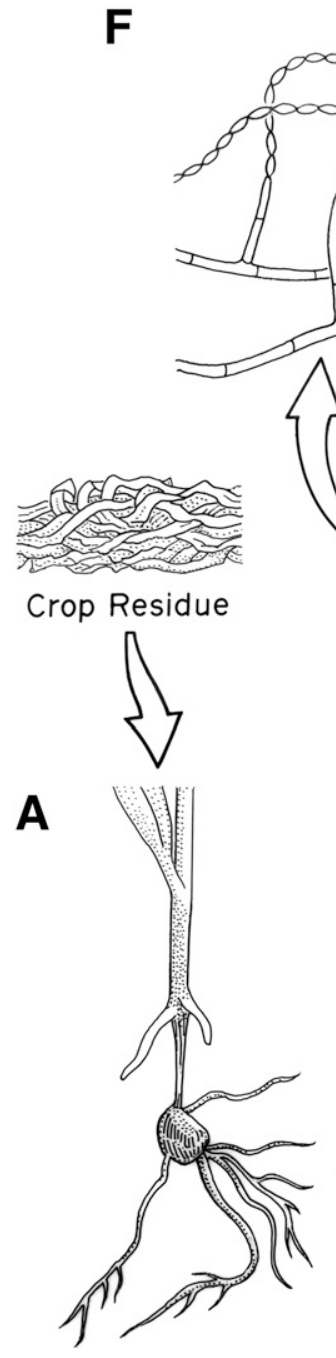

\section{Seedling Blight}

$\mathbf{E}$
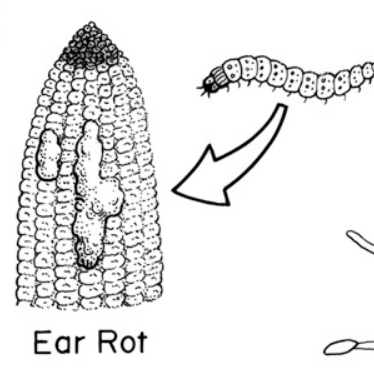

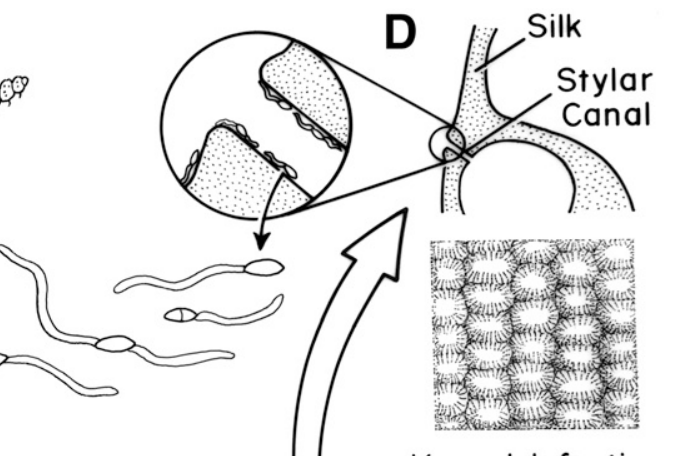

Conidiation
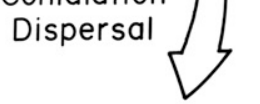

Hovers

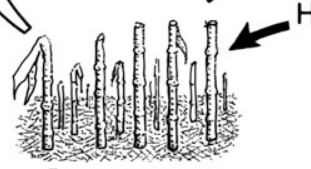

1
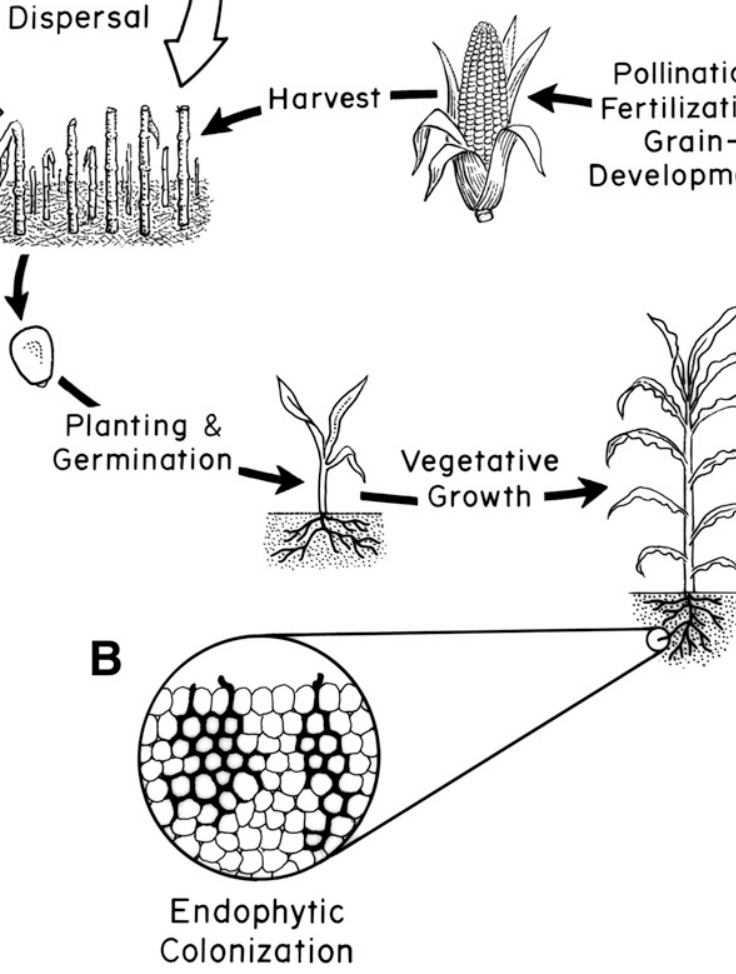

Pollination

Fertilization GrainDevelopment

\section{FIGURE 1}

Kernel Infection

"Starbursting"

The Fusarium verticillioides disease cycle, centered on the life cycle of maize. A, Seed germinating in Fusarium-infested soils may develop an aggressive rot and seedling blight. B, Endophytic colonization occurs under nondisease-promoting conditions. C, Stalk wounds from mechanical damage or insect feeding become infection courts for $F$. verticillioides and may result in stalk rot. D, At the silk stage, the fungus can colonize maize kernels via the stylar canal, giving rise to the "starburst" pattern on kernels. E, Larvae of the European corn borer moth feed on leaves, stalks, ears, and collar tissues, providing infection courts for $F$. verticillioides stalk and ear rots. F, After harvest, the fungus is capable of surviving and sporulating on crop residue, providing inoculum for subsequent infections. 
In addition to the above-described infection mechanisms, additional insects beyond lepidopterans can contribute to $F$. verticillioides infection. The feeding of adult thrips on maize ears promotes the occurrence of silk-cut, providing wounds by which $F$. verticillioides infects and causes ear rot (Parsons and Munkvold 2010, 2012). Furthermore, volatiles released by the fungus were demonstrated to serve as attractants to beetles (Bartelt and Wicklow 1999). Carpophilus dimidiatus, a nitidulid pest of maize, exhibits a strong attraction to F. verticillioides-inoculated grain, with consumption of infected grain promoting faster development and higher fecundity than noninfected grain (Ako et al. 2003). Interestingly, a strain of $F$. verticillioides has been reported as entomopathogenic to maize-feeding grasshoppers, approaching 60\% mortality in feeding assays (Pelizza et al. 2011). These data, in conjunction with known methods of dissemination of $F$. verticillioides inoculum, suggest a range of symbiotic interactions between the fungus and other maize-associated organisms.

$F$. verticillioides infection of maize also can occur through existing openings. In the context of disease, stalk and ear rots primarily arise through infection courts created by mechanical wounding such as insect feeding. Regarding asymptomatic colonization, F. verticillioides is described as entering the host through root openings such as cracks and through lateral roots and root hairs (Oren et al. 2003). Exploitation of existing openings extends to infection of aerial tissues, with microscopy revealing that, at least under growth-chamber conditions, $F$. verticillioides hyphae are capable of infecting maize through leaf stomata or trichomes (Nguyen et al. 2016a,b). Interestingly, the fungus is not known to utilize enzymatic activity to penetrate host cells but, recently, direct penetration through appressoria-like structures was observed by $F$. verticillioides and other Fusarium spp. (Nguyen et al. 2016a).

Outside of conditions conducive to disease, $F$. verticillioides is capable of asymptomatic colonization as an endophyte and can contribute to host fitness through growth promotion and induction of defense-associated changes such as lignin deposition in the cell wall (Yates et al. 1997). In that study, seedlings grown from seed inoculated with $F$. verticillioides exhibited reduced growth at early stages but, by 21 days after planting, the shoot diameter, root growth, and dry weight of inoculated plants all matched or surpassed the uninfected plants. These data outline a tenuous period early in host development where the plant-fungus association is first established and, if this period passes without development of disease, the endophytic association may proceed in a benign or even beneficial manner to the host.

Microconidial inoculum is clearly very important in the life and disease cycles of F. verticillioides (Fig. 1F). Based on sampling of airspace above maize fields, the microconidial density and, thus, inoculum levels are highest during times of mechanical disturbance, particularly detasseling or pollination, harvest, and shelling (Donát et al. 2012). Among maize residue, environmental conditions determine the abundance of $F$. verticillioides conidiation and, although such factors act synergistically, temperature appears to most strongly affect spore production, with an optimum of approximately $30^{\circ} \mathrm{C}$ (Rossi et al. 2009).

Unlike the distantly related homothallic $F$. graminearum, F. verticillioides is heterothallic, requiring Mat1-1 and Mat1-2 mating types for sexual reproduction (Leslie and Summerell 2006). Such obligatory out-crossing combined with other developmental factors such as female fertility are likely contributors to the phenomenon wherein perithecia of $F$. verticillioides are rarely observed in nature even though the fungus readily mates in the laboratory. Studies of mating type distribution in Argentina and the Philippines suggest that $F$. verticillioides in maize fields undergoes infrequent sexual reproduction, while vegetative compatibility analyses, in contrast, suggest that sexual reproduction and recombination are more common (Chulze et al. 2000; Cumagun 2008). Overall, it is clear that, unlike $F$. graminearum, where ascospores function as primary inoculum, sexual reproduction in maize fields contributes to $F$. verticillioides genetic diversity but does not constitute an essential component of the disease cycle (Munkvold 2003a).
The maize- $F$. verticillioides interaction is an excellent illustration of the endophytic continuum concept, whereby asymptomatic endophytic growth is hypothesized to result from a balance of virulence and defense responses, with particular conditions tilting the balance and provoking a transition to pathogenesis (Schulz and Boyle 2005). Such a balance can result from coevolution of the endophyte and plant (Pamphile and Azevedo 2002) and, because F. verticillioides can be isolated from surface-sterilized stalks and kernels of teosinte, the association with maize likely predates agricultural cultivation, suggesting an ancestral origin of the interaction (Desjardins et al. 2000). This association is likely dictated, in part, by various host factors, because infection success varies across cultivars (King and Scott 1981). Despite its dominant association with maize, it is worth noting that $F$. verticillioides is capable of asymptomatic infections in other monocots and even sugar beet (Dastjerdi and Karlovsky 2015); however, such reports warrant further investigation owing to the limitations of morphological species identifications and the potential for yetunrecognized cryptic species, as was the case with $F$. musae, the banana pathogen previously identified as $F$. verticillioides (Van Hove et al. 2011).

Understanding the life and disease cycles of $F$. verticillioides is necessary for the development of successful control strategies. Chemical control of Fusarium diseases in general has been described as "spectacularly unsuccessful," with control methods relying on agronomic practices and host resistance where possible (Leslie and Summerell 2013). As mentioned, F. verticillioides frequently infects maize through wounds left by insect feeding, and lepidopteran-toxic transgenic maize has been shown to reduce disease incidence and fumonisin accumulation under high pest pressure conditions (Wu 2006). Cultivars with tighter, more complete husks also present a physical barrier to thrips and insect feeding which, in turn, reduces the level of $F$. verticillioides infection (Munkvold 2003b). Similarly, maize genotypes having a narrower stylar canal are more resistant to infection (Duncan and Howard 2010), as noted earlier. Because maize residue provides an inoculum source for the pathogen, biological control strategies are proposed that use rhizosphere bacteria to reduce F. verticillioides population levels and, thus, reduce fumonisin accumulation in crops (Pereira et al. 2010). Agronomically, field studies across a range of regions in the United States identified earlier planting dates as consistently reducing the level of insect damage, disease severity, and fumonisin accumulation (Parsons and Munkvold 2012). Overall, these studies and others have shown that, as the $F$. verticillioides-maize interaction is better characterized and understood, we are able to develop or adapt control strategies for more effective management of $F$. verticillioides infection and fumonisin contamination of the kernels.

Molecular and biochemical mechanisms of host-fungus interactions. Plant-microbe interactions classically rely on microbial secretion of metabolites and enzymes; for example, the $F$. verticillioides fungalysin that cleaves maize class IV chitinases involved in host defense (Naumann et al. 2011). This novel metalloprotease, in turn, can be inhibited by wheat antimicrobial peptides, which have orthologs in maize (Slavokhotova et al. 2014). In addition to secreted effectors and their inhibitors, cross-kingdom signaling molecules appear to play a significant role in determining the outcomes of the $F$. verticillioides interaction with maize. Oxylipins, produced by both the host and pathogen, affect pathogenesis-related $(P R)$ gene expression and toxin production, respectively. In the case of Aspergillus ochraceus on Triticum durum, the deletion of a fungal LOX gene rendered the pathogen undetected by the host (Scala et al. 2014). In contrast, $F$. verticillioides exhibits reduced conidiation and fumonisin production when inoculated onto a maize line with disrupted 9-LOX, suggesting that these plant-derived signal molecules act as "susceptibility factors" through induction of pathogenicity-associated cell processes (Gao et al. 2007). Transcriptional analysis revealed that expression of genes controlled by these molecules exhibit a "zig-zag" pattern resembling that of the immunity-susceptibility model of plant-pathogen 
interactions, with fungus and host each producing and perceiving each other's oxylipins during the infection process (Scala et al. 2015).

Maize defense activity against $F$. verticillioides is typical of interactions with necrotrophs. For example, the plant exhibits nonspecific responses such as induction of the PR protein PRm, thought to accumulate as a general response to fungal invasion (Murillo et al. 1999). In fact, maize cultivars expressing resistance to $F$. verticillioides were found to have elevated expression levels of $P R$ genes and peroxidase prior to inoculation, and interestingly, resistant cultivars exhibited weaker induction of these genes upon pathogen challenge as compared with susceptible cultivars (Maschietto et al. 2016). Although it is unclear whether this is an artifact of the already-high expression in resistant plants or indicative of a difference in the speed of transcript accumulation between susceptible and resistant cultivars upon inoculation, the basic point is that the plant is primed for nonspecific response. Similarly, PR-4 responds to wounding and even $F$. verticillioides metabolites and is presumed to act as prophylaxis against fungal infection following environmental insult (Bravo et al. 2003). Fumonisins themselves are known to modulate host responses to $F$. verticillioides infection, with $\mathrm{FB}_{1}$ treatment increasing the ratio of acidic to basic isoforms of $\beta$-1,3-glucanases involved in defense activity (Sánchez-Rangel et al. 2012). Furthermore, exogenous application of $\mathrm{FB}_{1}$ to germinating maize caused a dose-dependent accumulation of salicylic acid associated with inhibition of ceramide synthase and increased accumulation of sphingoid bases (de la TorreHernandez et al. 2010). Overall, $\mathrm{FB}_{1}$ appears to enhance maize cell death and necrotrophic fungal colonization of the plant by activating the salicylic acid defense pathway and, in this manner, $\mathrm{FB}_{1}$ may be considered a necrotrophic effector (Arias et al. 2012). Characterization of such effector-like activity and how $\mathrm{FB}_{1}$ modulates host defense (Michaelson et al. 2016) assists in understanding $F$. verticillioides virulence on maize and likewise contributes to better understanding of how endophytism, as a part of the continuum, is modulated in this pathosystem.

Functional characterization of $F$. verticillioides genes conferring host and environmental perception and response provide insight into the process of plant colonization and virulence. We outline genes of interest and their characterized functions in Table 1 and Figure 2. For example, the recently characterized $F v C P 01$ (FVEG_10866) and FvCPO2 (FVEG_12888) genes encode dual-function catalaseperoxidases responsible for conferring resistance to hydrogen peroxide $\left(\mathrm{H}_{2} \mathrm{O}_{2}\right)$, but the fungus differentially utilizes the two enzymes depending on the nature of the oxidative stress (Gao et al. 2017b). The intracellular $\mathrm{FvCp} 01$ is most responsive to in vitro oxidative challenge with $\mathrm{H}_{2} \mathrm{O}_{2}$. In contrast, $F v C P O 2$ encodes an extracellular isoform of the catalase-peroxidase, and the gene is induced when the fungus infects maize germlings, presumably in response to plant-derived $\mathrm{H}_{2} \mathrm{O}_{2}$ or other plant signals. Within $F$. verticillioides, the signaling proteins FlbA1 and FlbA2 (FVEG_08855 and FVEG_06192, respectively) are involved in regulating fungal defense responses during early infection of maize but they also affect conidiation and fumonisin production (Mukherjee et al. 2011). As noted previously, deletion mutants for the transcriptional regulators encoded by $S G E 1$ and $F v V E 1$ exhibited reduced fumonisin production and virulence, along with defects in morphology and conidiation (Brown et al. 2014; Li et al. 2006). It is worth noting that such regulators modulating pathways involved with host interactions, development, and survival are also likely heavily involved in the balance and transition between asymptomatic endophyte and necrotrophic pathogen.

Genes involved in functions such as hyphal differentiation and sporulation are consistently linked to virulence, suggesting that the F. verticillioides pathogenic lifestyle relies on differential regulation of otherwise "essential" cell machinery (Table 1; Fig. 2). Mutation of the morphogenesis regulator FvStuA results in reduced seedling virulence, conidiation, and fumonisin production (MalapiWight et al. 2014) (M. Rath and S. E. Gold, unpublished data). Similar phenotypes were observed in deletion mutants for genes encoding stress tolerance activities such as the adenylate cyclase Fac1 (noted earlier), the hexose transporter homolog Fst1 (FVEG_08441), and the HAP transcriptional regulator complex (FVEG_00807, FVEG_08087, and FVEG_09223) (Choi and Xu 2010; Niu et al. 2015; Ridenour and Bluhm 2014). The FUG1 gene, also noted earlier, appears to be central in regulation of a number of cell processes linked to pathogen success because mutants exhibit a transcriptomic "reprogramming" leading to deficiencies in virulence, conidiation, toxin production, and stress tolerance (Ridenour and Bluhm 2017). In general, genes encoding processes affecting stress tolerance and metabolism likely also enhance virulence, given that maize as well as its associated phytobiome can present physical and biochemical challenges to would-be colonizers.

\section{MAIZE PHYTOCHEMICALS AS DRIVERS OF FUNGAL GENOMES, HOST INTERACTIONS, AND FITNESS ADAPTATIONS}

Plants are capable of producing a diverse array of secondary metabolites as chemical defenses against phytopathogenic microbes, and these defensive compounds are functionally categorized into metabolites produced and stockpiled as a mechanism of anticipated defense (phytoanticipins) or synthesized de novo as needed upon pathogenic challenges (phytoalexins) (VanEtten et al. 1994). Maize and wheat are major agricultural cereal crops producing benzoxazinone cyclic hydroxamic acids as phytoanticipins, although de novo production of the compounds has been shown as an inducible response (Ahmad et al. 2011; Niemeyer 2009). Benzoxazinones can deter insect herbivory and are implicated in resistance to various fungal and bacterial diseases (Niemeyer 2009). The primary compounds produced by maize and wheat are 2,4-dihydroxy-7-methoxy-1,4-benzoxazin-3one (DIMBOA) and 2,4-dihydroxy-1,4-benzoxazin-3-one (DIBOA), whereas rye produces only DIBOA (Niemeyer 2009). The benzoxazinones are unstable once released, and DIMBOA and DIBOA spontaneously degrade to the more stable corresponding benzoxazolinones 6-methoxy-benzoxazolin-2-one (MBOA) and BOA, respectively. Abundant production of the benzoxazinones occurs during early stages of maize seedling development, possibly serving to protect the plant during this vulnerable phase of growth and establishment (Cambier et al. 2000). Total benzoxazinone concentrations within the maize plant decrease as it matures.

Only a limited number of species, most of which are Fusarium spp. associated with maize and wheat, are able to tolerate MBOA and BOA at high concentrations ( $\geq 0.75 \mathrm{mg} / \mathrm{ml}$ ) (Glenn et al. 2001; Vilich et al. 1999). Tolerance is due to hydrolysis and decarbonylation of the fivemembered oxazole ring of MBOA and BOA, followed by addition of a malonyl group that yields the nontoxic metabolites $\mathrm{N}$-(2-hydroxy-4methoxyphenyl) malonamic acid (HMPMA) and $N$-(2-hydroxyphenyl) malonamic acid (HPMA), respectively (Glenn and Bacon 2009; Glenn et al. 2002, 2003). The maize pathogens $F$. verticillioides and $F$. subglutinans are among the most tolerant species due to their unique possession of the $F D B 1$ and FDB2 loci that confer the enzymatic biotransformation of (M) BOA into H(M)PMA (Glenn et al. 2001, 2016; Vilich et al. 1999). Recent transcriptional and genomic studies have shown that these two loci each encompass gene clusters, with the $F$. verticillioides FDB1 cluster encompassing nine contiguous genes coexpressed in response to BOA (Glenn et al. 2016) and the FDB2 cluster containing 16 genes, 13 of which are coexpressed (Glenn and Bacon 2009; Glenn et al. 2016).

The only gene in the $F$. verticillioides FDB1 cluster found to be essential for tolerance to BOA was MBL1 (FVEG_08291), which encodes a metallo- $\beta$-lactamase that hydrolyzes the BOA oxazole ring, resulting in formation of the intermediate compound 2aminophenol (Glenn et al. 2016). The lactamase gene family will be discussed in more detail below. Deletion or disruption of the other eight $F D B 1$ cluster genes did not affect tolerance or biotransformation of BOA. Because six of the nine $F D B 1$ cluster genes, including $M B L 1$, have paralogs in the larger $F D B 2$ cluster, functional redundancy of the encoded proteins could explain why most $F D B 1$ 
and FDB2 genes were not essential for tolerance to BOA. Furthermore, only the NAT1 gene (FVEG_12636) in the FDB2 cluster was essential for detoxification of BOA (Glenn and Bacon 2009). The Nat1 protein modifies the 2-aminophenol intermediate after the hydrolysis of BOA by Mbl1. Nat1 does not have any functionally redundant paralogs in $F$. verticillioides and is a unique $N$-malonyltransferase with specificity for malonyl-CoA as a donor substrate for the malonylation of 2-aminophenol, instead of the typical $\mathrm{N}$-acetyltransferase activity using acetyl-CoA conferred by most of the characterized prokaryotic and eukaryotic NATs (Karagianni et al. 2015). Although deletion of either MBL1 or NAT1 eliminates tolerance to BOA, the virulence of $F$. verticillioides against maize seedlings was not significantly affected. In contrast, the NATI ortholog of F. pseudogra- minearum was required for full virulence against wheat, as determined through assays using a $\Delta$ nat 1 mutant (Kettle et al. 2015a). Interestingly, F. pseudograminearum does not possess an ortholog of the F. verticillioides $M B L 1$ but, instead, possesses an ortholog of another metallo- $\beta$-lactamase gene, MBL2 (FVEG_12637), located in the $F D B 2$ cluster (Glenn et al. 2016). In F. pseudograminearum, the $M B L 2$ gene (FPSE_08124) is responsible for hydrolysis of benzoxazolinones (Kettle et al. 2015b).

Although the impact on virulence toward host plants may vary between Fusarium spp., detoxification of benzoxazinone and benzoxazolinone compounds was shown to be a major factor contributing to the dominance of tolerant fungi in maize field environments (Saunders and Kohn 2009; Saunders et al. 2010). The detoxification of these

TABLE 1

Genes affecting Fusarium verticillioides virulence, secondary metabolite production, stress responses, growth, and sporulation

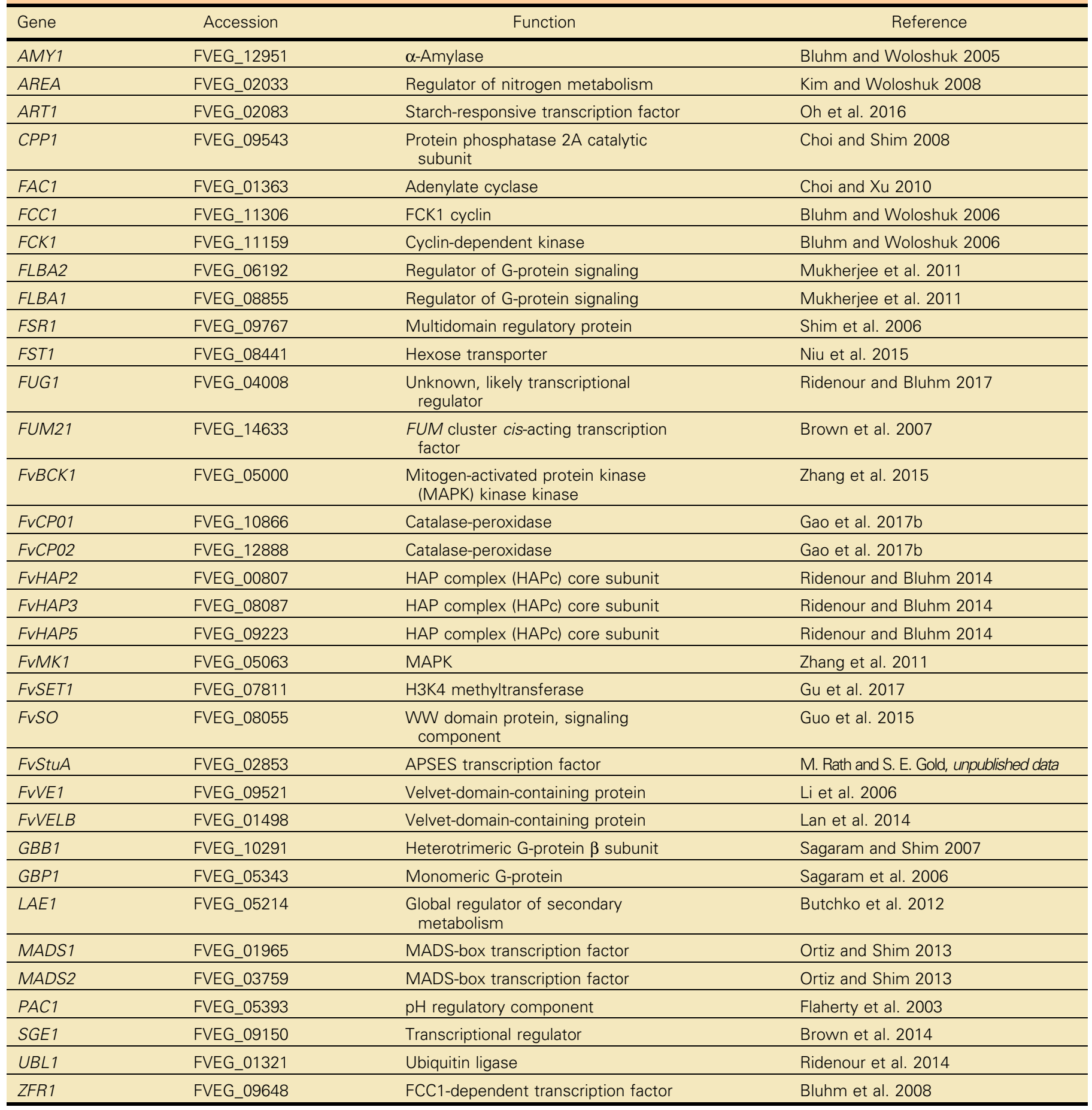


phytochemicals may provide a competitive advantage over species having sensitivity to the compounds by increasing the fitness of tolerant fungi for niche competition and early colonization of plant tissues. In this manner, the phytochemicals act as xenobiotic filters that suppress or delay colonization of plant tissues by sensitive fungi. For example, the biotrophic corn smut fungus Ustilago maydis is sensitive to these maize compounds, and coinoculation experiments on maize indicated that $F$. verticillioides greatly reduced the biomass of $U$. maydis, thus slowing its disease progress and gall development while, at the same time, the biomass of $F$. verticillioides increased in the presence of $U$. maydis (May and Nelson 2014). As colonization progressed, the degradation of the benzoxazinones and benzoxazolinones by $F$. verticillioides facilitated more prolific $U$. maydis sporulation in the galls. In the course of this extended infection, there was a significant increase in available carbon to F. verticillioides due to the smut's physiological and developmental effects on the plant, thus providing a nutritional and growth benefit to $F$. verticillioides.

A survey of 49 Fusarium genomes identified only three species ( $F$. verticillioides, $F$. subglutinans, and $F$. camptoceras) having both the $F D B 1$ and $F D B 2$ gene clusters (Glenn et al. 2016). Little is known about $F$. camptoceras other than reports of its recovery from decaying bananas and cacao in subtropical and tropical regions (Leslie and Summerell 2006). Most of the surveyed species $(n=34)$ only had the $F D B 2$ cluster either entirely or partially, and the cluster is postulated to have originated from duplication of the $F D B 1$ gene cluster in the common ancestor of these Fusarium spp. The limited distribution of the $F D B 1$ cluster to just three species is likely due to loss of the cluster in most species. The remaining 12 species in the survey lacked both clusters. Interestingly, whereas no Fusarium sp. possessed just the FDB1 cluster, another ascomycete pathogen of maize, Colletotrichum graminicola, possessed an FDB1 gene cluster but lacked the $F D B 2$ cluster (Glenn et al. 2016). The $F D B 1$ cluster of $C$. graminicola was structurally syntenic to the $F D B 1$ clusters of the three Fusarium spp., even to the degree that the common genes shared high nucleotide identity. Such identity conservation, combined with phylogenies of the FDB1 genes, supports the hypothesis that $C$. graminicola acquired the $F D B 1$ cluster from Fusarium by HGT. Similarly, HGT was postulated for the $F D B 2$ cluster, involving acquisition of the

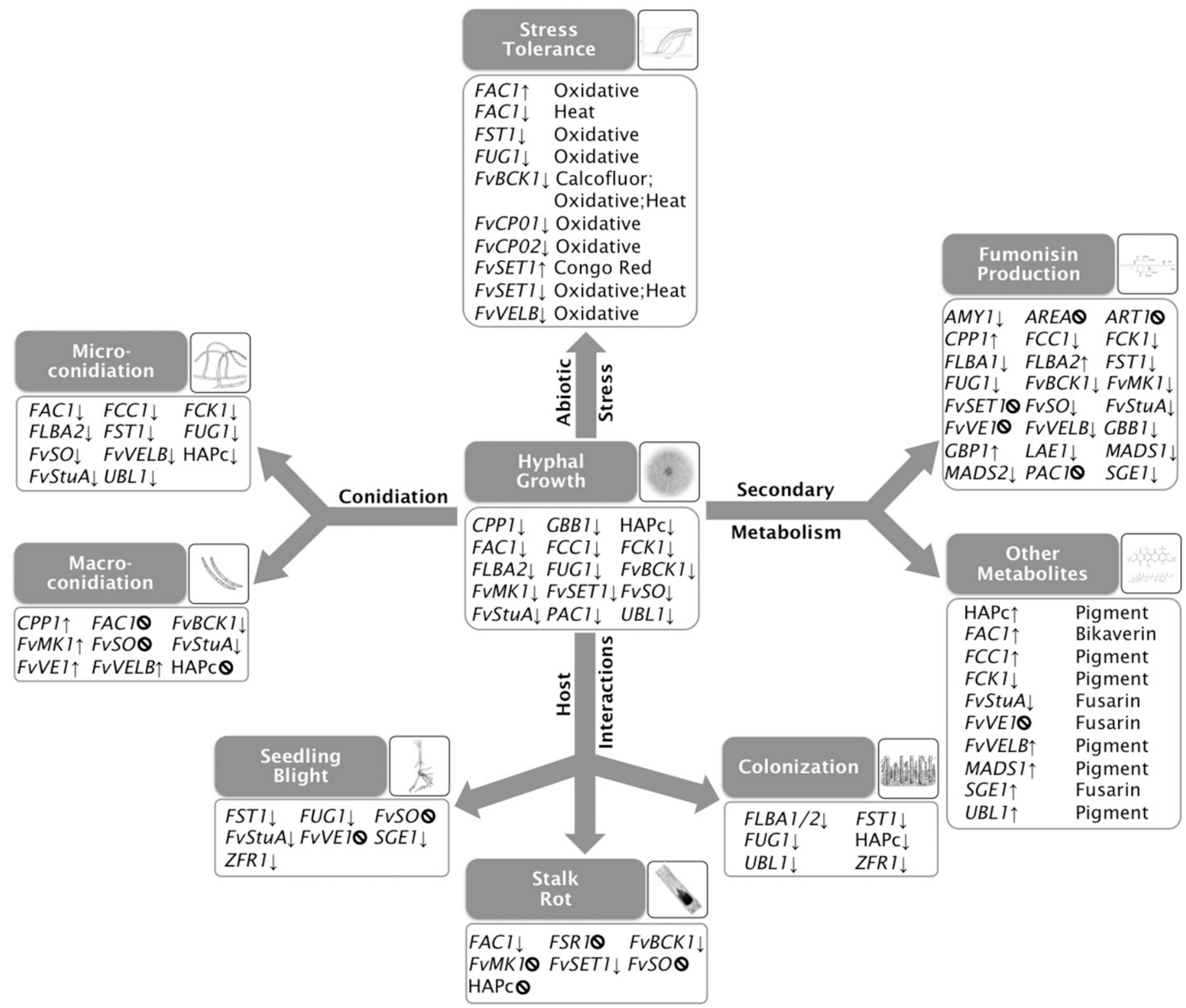

FIGURE 2

Fusarium verticillioides genes involved in virulence and toxin production often serve multiple roles. Genes are outlined with regard to effects on development, physiology, and phytopathology. Deletion of a gene and the noted change in the mutant's phenotype is noted as increased ( $\uparrow$ ), decreased $(\downarrow)$, or eliminated $(Q)$ for the various characteristics. The HAP complex (HAPC) is shown as a whole instead of the individual subunit genes. 
cluster by Aspergillus from Fusarium, with A. kawachii being the only known species retaining the cluster with conserved synteny to the Fusarium FDB2 cluster.

The xenobiotic filtering imposed by the maize phytochemicals undoubtedly exerts evolutionary pressure on the affected fungi and may, in this way, facilitate horizontal transfer of genes or gene clusters that enhance fungal fitness or virulence by conferring tolerance to the xenobiotic compounds. Understanding these ecological and evolutionary factors is important for identifying and evaluating control measures targeting pathogenic fungi. For example, efforts to breed maize to produce higher concentrations of DIMBOA as a strategy to decrease insect herbivory (Niemeyer 2009) may also confer increased suppression of sensitive fungi and preferentially filter for tolerant fungi such as $F$. verticillioides, resulting in higher infection frequencies and higher levels of fumonisins in maize.

\section{LACTAMASES - AN EXAMPLE OF GENE FAMILY EXPANSION IN FUSARIUM SPP.}

Archetypical $\beta$-lactamases are well studied in bacteria for their ability to hydrolyze the lactam moiety in four-membered ring structures common to $\beta$-lactam antibiotics (e.g., penicillin), thus abolishing the antimicrobial activity (Tipper 1985). Since their introduction in the $1940 \mathrm{~s}$, these $\beta$-lactam antibiotics have become a cornerstone of modern medicine. They function by disrupting bacterial peptidoglycan cell wall biosynthesis but their efficacy is now diminished due to the evolution and spread of $\beta$-lactamases among bacteria (Fernandes et al. 2013). Interestingly, we have discovered that the $F$. verticillioides genome contains more than 40 genes encoding enzymes with domain homology to two different classes of lactamases: the serine based $\beta$-lactamases (PFAM domain PF00144) or the metallo- $\beta$-lactamases (PF00753). However, Fusarium cell walls are structurally unrelated to those of bacteria, and $\beta$-lactam antibiotics generally have no effect on Fusarium growth. These observations raise the question: why do fungi possess $\beta$-lactamases when they are not sensitive to $\beta$-lactams?

As was previously mentioned, the hydrolytic function of the metallo- $\beta$-lactamase Mbl1 in F. verticillioides is essential for tolerating maize benzoxazolinone compounds by hydrolyzing the oxazole ring (Glenn et al. 2016). It is important to note that these phytochemicals are not $\beta$-lactams, meaning they do not contain a four-membered lactam ring. Rather, the benzoxazolinones have a five-membered $\gamma$-lactam ring. Despite their protein sequence homology to classical $\beta$-lactamases, many of the fungal lactamases may be functionally novel by targeting a range of lactam substrates, including potentially diverse lactam xenobiotics in the environment. Detailed evaluation of these enzymes, including their presence, origin, and significance among Fusarium spp., is a current focus of our research group (Gao et al. 2017a).

Evaluation of available genomes has revealed that Fusarium spp. are highly enriched for lactamase genes compared with other genera. Searches for the two PFAM domains (PF00144 and PF00753) identified 38 genes in $F$. graminearum, 42 genes in $F$. pseudograminearum, 45 genes in F. fujikuroi, 46 genes in F. verticillioides, 63 genes in $F$. oxysporum, and 88 genes in $F$. solani mpVI (Gao et al. 2017a). Despite such abundance of putative lactamase-encoding genes, only $M B L 1$ in $F$. verticillioides and $M B L 2$ in F. pseudograminearum have been functionally characterized. The amplification of this gene family among fungi suggests its ecological importance because of the strong positive correlation between the number of lactamase genes and exposure to the metabolite-rich soil environment. For example, obligate foliar pathogens such as Puccinia graminis and Blumeria graminis possess very few $(\leq 5)$ lactamaseencoding genes, whereas soilborne members of their respective orders such as Atractiellales sp. and Sclerotinia sclerotiorum possess at least twice as many lactamase genes $(>11)$. The few lactamases that are encoded in the foliar obligates likely involve central metabolism features such as RNA processing and are not related to xenobiotic resistance. F. verticillioides, as both a soil inhabitant and seedborne endophyte, is inevitably exposed to various kinds of xenobiotics from soil microbes, other microbial endophytes, and the host plant. Hence, we hypothesize that many of its lactamases confer resistance to inhibitory xenobiotics that are present in environments such as the soil with large cohorts of interacting organisms (Gao et al. 2017a).

\section{CONCLUSION}

This review has highlighted significant research advancements enhancing our understanding of $F$. verticillioides, from the health and economic threats of fumonisin contamination to its basic biology and the molecular underpinnings of pathogenicity and environmental fitness. As a model phytopathogen having both endophytic and necrotrophic aspects of its host associations, $F$. verticillioides presents an opportunity to advance scientific understanding across multiple lines of important research, with such knowledge essential to developing effective disease control and management of mycotoxin contamination. Data regarding fitness strategies employed by $F$. verticillioides to persist in the maize rhizosphere and phylloplane are also valuable in understanding endophyte biology and the lifestyles of other soilborne fungi intimately associated with their host plants.

\section{ACKNOWLEDGMENTS}

We thank C. L. Gubbins Hahn for illustrating the F. verticillioides disease cycle and W. Garfinkel-Gold for digitizing the illustration.

\section{LITERATURE CITED}

Abbas, H. K., Tanaka, T., Duke, S. O., Porter, J. K., Wray, E. M., Hodges, L., Sessions, A. E., Wang, E., Merrill, A. H., Jr., and Riley, R. T. 1994. Fumonisin-and AAL-toxin-induced disruption of sphingolipid metabolism with accumulation of free sphingoid bases. Plant Physiol. 106:1085-1093.

Ahmad, S., Veyrat, N., Gordon-Weeks, R., Zhang, Y., Martin, J., Smart, L., Glauser, G., Erb, M., Flors, V., Frey, M., and Ton, J. 2011. Benzoxazinoid metabolites regulate innate immunity against aphids and fungi in maize. Plant Physiol. 157:317-327.

Ako, M., Schulthess, F., Gumedzoe, M. Y. D., and Cardwell, K. F. 2003. The effect of Fusarium verticillioides on oviposition behaviour and bionomics of lepidopteran and coleopteran pests attacking the stem and cobs of maize in West Africa. Entomol. Exp. Appl. 106:201-210.

Arias, S. L., Mary, V. S., Otaiza, S. N., Wunderlin, D. A., Rubinstein, H. R., and Theumer, M. G. 2016. Toxin distribution and sphingoid base imbalances in Fusarium verticillioides-infected and fumonisin B1-watered maize seedlings. Phytochemistry 125:54-64.

Arias, S. L., Theumer, M. G., Mary, V. S., and Rubinstein, H. R. 2012. Fumonisins: Probable role as effectors in the complex interaction of susceptible and resistant maize hybrids and Fusarium verticillioides. J. Agric. Food Chem. 60:5667-5675.

Baldwin, T. T., Zitomer, N. C., Mitchell, T. R., Zimeri, A.-M., Bacon, C. W., Riley, R. T., and Glenn, A. E. 2014. Maize seedling blight induced by Fusarium verticillioides: Accumulation of fumonisin B1 in leaves without colonization of the leaves. J. Agric. Food Chem. 62:2118-2125.

Bartelt, R. J., and Wicklow, D. T. 1999. Volatiles from Fusarium verticillioides (Sacc.) Nirenb. and their attractiveness to nitidulid beetles. J. Agric. Food Chem. 47:2447-2454.

Bennett, J. W., and Klich, M. 2003. Mycotoxins. Clin. Microbiol. Rev. 16: 497-516.

Bluhm, B. H., Kim, H., Butchko, R. A., and Woloshuk, C. P. 2008. Involvement of ZFR1 of Fusarium verticillioides in kernel colonization and the regulation of FST1, a putative sugar transporter gene required for fumonisin biosynthesis on maize kernels. Mol. Plant Pathol. 9:203-211.

Bluhm, B. H., and Woloshuk, C. P. 2005. Amylopectin induces fumonisin B1 production by Fusarium verticillioides during colonization of maize kernels. Mol. Plant-Microbe Interact. 18:1333-1339.

Bluhm, B. H., and Woloshuk, C. P. 2006. Fck1, a C-type cyclin-dependent kinase, interacts with Fcc1 to regulate development and secondary metabolism in Fusarium verticillioides. Fungal Genet. Biol. 43:146-154.

Bömke, C., Rojas, M. C., Hedden, P., and Tudzynski, B. 2008. Loss of gibberellin production in Fusarium verticillioides (Gibberella fujikuroi MP-A) 
is due to a deletion in the gibberellic acid gene cluster. Appl. Environ. Microbiol. 74:7790-7801.

Bourett, T. M., Sweigard, J. A., Czymmek, K. J., Carroll, A., and Howard, R. J. 2002. Reef coral fluorescent proteins for visualizing fungal pathogens. Fungal Genet. Biol. 37:211-220.

Bravo, J. M., Campo, S., Murillo, I., Coca, M., and San Segundo, B. 2003. Fungus- and wound-induced accumulation of mRNA containing a class II chitinase of the pathogenesis-related protein 4 (PR-4) family of maize. Plant Mol. Biol. 52:745-759.

Brown, D. W., Busman, M., and Proctor, R. H. 2014. Fusarium verticillioides SGE1 is required for full virulence and regulates expression of protein effector and secondary metabolite biosynthetic genes. Mol. Plant-Microbe Interact. 27:809-823.

Brown, D. W., Butchko, R. A., Busman, M., and Proctor, R. H. 2007. The Fusarium verticillioides FUM gene cluster encodes a Zn(II)2Cys6 protein that affects $F U M$ gene expression and fumonisin production. Eukaryot. Cell 6:1210-1218.

Brown, D. W., Butchko, R. A., Busman, M., and Proctor, R. H. 2012. Identification of gene clusters associated with fusaric acid, fusarin, and perithecial pigment production in Fusarium verticillioides. Fungal Genet. Biol. 49:521-532.

Brown, D. W., Cheung, F., Proctor, R. H., Butchko, R. A. E., Zheng, L., Lee, Y., Utterback, T., Smith, S., Feldblyum, T., Glenn, A. E., Plattner, R. D., Kendra, D. F., Town, C. D., and Whitelaw, C. A. 2005. Comparative analysis of 87,000 expressed sequence tags from the fumonisin-producing fungus Fusarium verticillioides. Fungal Genet. Biol. 42:848-861.

Brown, D. W., Lee, S. H., Kim, L. H., Ryu, J. G., Lee, S., Seo, Y., Kim, Y. H., Busman, M., Yun, S. H., Proctor, R. H., and Lee, T. 2015. Identification of a 12-gene fusaric acid biosynthetic gene cluster in Fusarium species through comparative and functional genomics. Mol. Plant-Microbe Interact. 28: 319-332.

Bulder, A., Arcella, D., Bolger, M., Carrington, C., Kpodo, K., Resnik, S., Riley, R., Wolterink, G., and Wu, F. 2012. Fumonisins (addendum). Safety evaluation of certain food additives and contaminants. Pages 325-794 in: World Health Organization Food Additives Series 65. World Health Organization, Geneva.

Butchko, R. A., Brown, D. W., Busman, M., Tudzynski, B., and Wiemann, P. 2012. Lae1 regulates expression of multiple secondary metabolite gene clusters in Fusarium verticillioides. Fungal Genet. Biol. 49:602-612.

Cambier, V., Hance, T., and de Hoffmann, E. 2000. Variation of DIMBOA and related compounds content in relation to the age and plant organ in maize. Phytochemistry 53:223-229.

Choi, Y.-E., and Shim, W.-B. 2008. Functional characterization of Fusarium verticillioides $C P P 1$, a gene encoding putative protein phosphatase $2 \mathrm{~A}$ catalytic subunit. Microbiology 154:326-336.

Choi, Y.-E., and Xu, J.-R. 2010. The cAMP signaling pathway in Fusarium verticillioides Is important for conidiation, plant infection, and stress responses but not fumonisin production. Mol. Plant-Microbe Interact. 23: 522-533.

Chulze, S. N., Ramirez, M. L., Torres, A., and Leslie, J. F. 2000. Genetic variation in Fusarium Section Liseola from no-till maize in Argentina. Appl. Environ. Microbiol. 66:5312-5315.

Cotten, T., and Munkvold, G. 1998. Survival of Fusarium moniliforme, $F$. proliferatum, and $F$. subglutinans in maize stalk residue. Phytopathology 88:550-555.

Cumagun, C. J. R. 2008. Female fertility and mating type distribution in a Philippine population of Fusarium verticillioides. J. Appl. Genet. 49:123-126.

Dastjerdi, R., and Karlovsky, P. 2015. Systemic infection of maize, sorghum, rice, and beet seedlings with fumonisin-producing and nonproducing Fusarium verticillioides strains. Plant Pathol. J. 31:334-342.

de la Torre-Hernandez, M. E., Rivas-San Vicente, M., Greaves-Fernandez, N., Cruz-Ortega, R., and Plasencia, J. 2010. Fumonisin B1 induces nuclease activation and salicylic acid accumulation through long-chain sphingoid base build-up in germinating maize. Physiol. Mol. Plant Pathol. 74:337-345.

Desjardins, A. E., Busman, M., Muhitch, M., and Proctor, R. H. 2007. Complementary host-pathogen genetic analyses of the role of fumonisins in the Zea mays-Gibberella moniliformis interaction. Physiol. Mol. Plant Pathol. 70:149-160.

Desjardins, A. E., and Plattner, R. D. 2000. Fumonisin B1-nonproducing strains of Fusarium verticillioides cause maize (Zea mays) ear infection and ear rot. J. Agric. Food Chem. 48:5773-5780.

Desjardins, A. E., Plattner, R. D., and Gordon, T. R. 2000. Gibberella fujikuroi mating population A and Fusarium subglutinans from teosinte species and maize from Mexico and Central America. Mycol. Res. 104:865-872.

Desjardins, A. E., Plattner, R. D., Nelsen, T. C., and Leslie, J. F. 1995. Genetic analysis of fumonisin production and virulence of Gibberella fujikuroi mating population A (Fusarium moniliforme) on maize (Zea mays) seedlings. Appl. Environ. Microbiol. 61:79-86.
De Vos, L., Steenkamp, E. T., Martin, S. H., Santana, Q. C., Fourie, G., van der Merwe, N. A., Wingfield, M. J., and Wingfield, B. D. 2014. Genome-wide macrosynteny among Fusarium species in the Gibberella fujikuroi complex revealed by amplified fragment length polymorphisms. PLoS One 9:e114682.

Diallo, M. S., Sylla, A., Sidibé, K., Sylla, B. S., Trepo, C. R., and Wild, C. P. 1995. Prevalence of exposure to aflatoxin and hepatitis B and $C$ viruses in Guinea, West Africa. Nat. Toxins 3:6-9.

Donát, M., Csaba, S., Zsuzsanna, K., Árpád, S., and János, B. 2012. Identification of airborne propagules of the Gibberella fujikuroi species complex during maize production. Aerobiologia 28:263-271.

Duncan, K. E., and Howard, R. J. 2010. Biology of maize kernel infection by Fusarium verticillioides. Mol. Plant-Microbe Interact. 23:6-16.

Fernandes, R., Amador, P., and Prudêncio, C. 2013. $\beta$-Lactams: Chemical structure, mode of action and mechanisms of resistance. Rev. Med. Microbiol. 24:7-17

Fernández-Surumay, G., Osweiler, G. D., Yaeger, M. J., Rottinghaus, G. E., Hendrich, S., Buckley, L. K., and Murphy, P. A. 2005. Fumonisin B-glucose reaction products are less toxic when fed to swine. J. Agric. Food Chem. 53: 4264-4271.

Flaherty, J. E., Pirttila, A. M., Bluhm, B. H., and Woloshuk, C. P. 2003. PAC1, a pH-regulatory gene from Fusarium verticillioides. Appl. Environ. Microbiol. 69:5222-5227.

Fourie, G., van der Merwe, N. A., Wingfield, B. D., Bogale, M., Tudzynski, B., Wingfield, M. J., and Steenkamp, E. T. 2013. Evidence for inter-specific recombination among the mitochondrial genomes of Fusarium species in the Gibberella fujikuroi complex. BMC Genomics 14:605.

Gao, M., Glenn, A. E., Blacutt, A. A., and Gold, S. E. 2017a. Fungal lactamases: their occurrence and function. Front. Microbiol. 8:1775.

Gao, S., Gold, S. E., and Glenn, A. E. 2017b. Characterization of two catalaseperoxidase-encoding genes in Fusarium verticillioides reveals differential responses to in vitro versus in planta oxidative challenges. Mol. Plant Pathol. doi.org/10.1111/mpp.12591

Gao, X., Shim, W.-B., Gobel, C., Kunze, S., Feussner, I., Meeley, R., Balint-Kurti, P., and Kolomiets, M. 2007. Disruption of a maize 9-lipoxygenase results in increased resistance to fungal pathogens and reduced levels of contamination with mycotoxin fumonisin. Mol. Plant-Microbe Interact. 20:922-933.

Gardiner, D. M., McDonald, M. C., Covarelli, L., Solomon, P. S., Rusu, A. G., Marshall, M., Kazan, K., Chakraborty, S., McDonald, B. A., and Manners, J. M. 2012. Comparative pathogenomics reveals horizontally acquired novel virulence genes in fungi infecting cereal hosts. PLoS Pathog. 8:e1002952.

Gelderblom, W., Abel, S., Smuts, C. M., Marnewick, J., Marasas, W., Lemmer, E. R., and Ramljak, D. 2001. Fumonisin-induced hepatocarcinogenesis: Mechanisms related to cancer initiation and promotion. Environ. Health Perspect. 109:291-300.

Gelderblom, W., Jaskiewicz, K., Marasas, W., Thiel, P., Horak, R., Vleggaar, R., and Kriek, N. 1988. Fumonisins-Novel mycotoxins with cancer-promoting activity produced by Fusarium moniliforme. Appl. Environ. Microbiol. 54: 1806-1811.

Gelderblom, W., Kriek, N., Marasas, W., and Thiel, P. 1991. Toxicity and carcinogenicity of the Fusarium moniliforme metabolite, fumonisin B1, in rats. Carcinogenesis 12:1247-1251.

Gelineau-van Waes, J., Voss, K., Stevens, V., Speer, M., and Riley, R. 2009. Maternal fumonisin exposure as a risk factor for neural tube defects. Adv. Food Nutr. Res. 56:145-181.

Gilbertson, R., Brown, W., Jr., Ruppel, E., and Capinera, J. 1986. Association of corn stalk rot Fusarium spp. and Western corn rootworm beetles in Colorado. Phytopathology 76:1309-1314.

Glenn, A. E. 2007. Mycotoxigenic Fusarium species in animal feed. Anim. Feed Sci. Technol. 137:213-240.

Glenn, A. E., and Bacon, C. W. 2009. FDB2 encodes a member of the arylamine $\mathrm{N}$-acetyltransferase family and is necessary for biotransformation of benzoxazolinones by Fusarium verticillioides. J. Appl. Microbiol. 107:657-671.

Glenn, A. E., Davis, C. B., Gao, M., Gold, S. E., Mitchell, T. R., Proctor, R. H., Stewart, J. E., and Snook, M. E. 2016. Two horizontally transferred xenobiotic resistance gene clusters associated with detoxification of benzoxazolinones by Fusarium species. PLoS One 11:e0147486.

Glenn, A. E., Gold, S. E., and Bacon, C. W. 2002. Fdb1 and Fdb2, Fusarium verticillioides loci necessary for detoxification of preformed antimicrobials from corn. Mol. Plant-Microbe Interact. 15:91-101.

Glenn, A. E., Hinton, D. M., Yates, I. E., and Bacon, C. W. 2001. Detoxification of corn antimicrobial compounds as the basis for isolating Fusarium verticillioides and some other Fusarium species from corn. Appl. Environ. Microbiol. 67:2973-2981.

Glenn, A. E., Meredith, F. I., Morrison, W. H., 3rd, and Bacon, C. W. 2003. Identification of intermediate and branch metabolites resulting from biotransformation of 2-benzoxazolinone by Fusarium verticillioides. Appl. Environ. Microbiol. 69:3165-3169. 
Glenn, A. E., Zitomer, N. C., Zimeri, A. M., Williams, L. D., Riley, R. T., and Proctor, R. H. 2008. Transformation-mediated complementation of a FUM gene cluster deletion in Fusarium verticillioides restores both fumonisin production and pathogenicity on maize seedlings. Mol. Plant-Microbe Interact. 21:87-97.

Grigoriev, I. V., Nordberg, H., Shabalov, I., Aerts, A., Cantor, M., Goodstein, D., Kuo, A., Minovitsky, S., Nikitin, R., Ohm, R. A., Otillar, R., Poliakov, A., Ratnere, I., Riley, R., Smirnova, T., Rokhsar, D., and Dubchak, I. 2012. The genome portal of the Department of Energy Joint Genome Institute. Nucleic Acids Res. 40:D26-D32.

Gu, Q., Tahir, H. A. S., Zhang, H., Huang, H., Ji, T., Sun, X., Wu, L., Wu, H., and Gao, X. 2017. Involvement of FvSet1 in fumonisin $B_{1}$ biosynthesis, vegetative growth, fungal virulence, and environmental stress responses in Fusarium verticillioides. Toxins (Basel) 9:43.

Guo, L., Breakspear, A., Zhao, G., Gao, L., Kistler, H. C., Xu, J.-R., and Ma, L.-J. 2016. Conservation and divergence of the cyclic adenosine monophosphateprotein kinase A (cAMP-PKA) pathway in two plant-pathogenic fungi: Fusarium graminearum and F. verticillioides. Mol. Plant Pathol. 17: 196-209.

Guo, L., Wenner, N., and Kuldau, G. A. 2015. FvSO regulates vegetative hyphal fusion, asexual growth, fumonisin $\mathrm{B}_{1}$ production, and virulence in Fusarium verticillioides. Fungal Biol. 119:1158-1169.

Harrison, L. R., Colvin, B. M., Greene, J. T., Newman, L. E., and Cole, J. R. 1990. Pulmonary edema and hydrothorax in swine produced by fumonisin B1, a toxic metabolite of Fusarium moniliforme. J. Vet. Diagn. Invest. 2: 217-221.

Howard, P. C., Eppley, R. M., Stack, M. E., Warbritton, A., Voss, K. A., Lorentzen, R. J., Kovach, R. M., and Bucci, T. J. 2001. Fumonisin B1 carcinogenicity in a two-year feeding study using F344 rats and B6C3F1 mice. Environ. Health Perspect. 109:277-282.

Jaskiewicz, K., Marasas, W., and Taljaard, J. 1987. Hepatitis in vervet monkeys caused by Fusarium moniliforme. J. Comp. Pathol. 97:281-291.

Karagianni, E. P., Kontomina, E., Davis, B., Kotseli, B., Tsirka, T., Garefalaki, V., Sim, E., Glenn, A. E., and Boukouvala, S. 2015. Homologues of xenobiotic metabolizing $N$-acetyltransferases in plant-associated fungi: Novel functions for an old enzyme family. Sci. Rep. 5:12900.

Kellerman, T., Marasas, W., Pienaar, J., and Naude, T. 1972. A mycotoxicosis of equidae caused by Fusarium moniliforme Sheldon. A preliminary communication. Onderstepoort J. Vet. Res. 39:205-208.

Kellerman, T. S., Marasas, W. F. O., Thiel, P., Gelderblom, W., and Cawood, M. 1990. Leukoencephalomalacia in two horses induced by oral dosing of fumonisin $\mathrm{B}_{1}$. Onderstepoort J. Vet. Res. 57:269-275.

Kensler, T. W., Roebuck, B. D., Wogan, G. N., and Groopman, J. D. 2011. Aflatoxin: A 50-year odyssey of mechanistic and translational toxicology. Toxicol. Sci. 120:S28-S48.

Kettle, A. J., Batley, J., Benfield, A. H., Manners, J. M., Kazan, K., and Gardiner, D. M. 2015a. Degradation of the benzoxazolinone class of phytoalexins is important for virulence of Fusarium pseudograminearum towards wheat. Mol. Plant Pathol. 16:946-962.

Kettle, A. J., Carere, J., Batley, J., Benfield, A. H., Manners, J. M., Kazan, K., and Gardiner, D. M. 2015b. A $\gamma$-lactamase from cereal infecting Fusarium spp. catalyses the first step in the degradation of the benzoxazolinone class of phytoalexins. Fungal Genet. Biol. 83:1-9.

Kim, H., and Woloshuk, C. P. 2008. Role of AREA, a regulator of nitrogen metabolism, during colonization of maize kernels and fumonisin biosynthesis in Fusarium verticillioides. Fungal Genet. Biol. 45:947-953.

King, S. B., and Scott, G. E. 1981. Genotypic differences in maize to kernel infection by Fusarium moniliforme. Phytopathology 71:796-799.

Kistler, H. C., Rep, M., and Ma, L.-J. 2013. Structural dynamics of Fusarium genomes. Pages 31-41 in: Fusarium: Genomics, Molecular and Cellular Biology. D. W. Brown and R. H. Proctor, eds. Caister Academic Press, Norfolk, UK.

Kriek, N. P., Kellerman, T. S., and Marasas, W. F. O. 1981a. A comparative study of the toxicity of Fusarium verticillioides ( $F$. moniliforme) to horses, primates, pigs, sheep and rats. Onderstepoort J. Vet. Res. 48: 129-131.

Kriek, N. P. J., Marasas, W. F. O., and Thiel, P. G. 1981b. Hepato-and cardiotoxicity of Fusarium verticillioides ( $F$. moniliforme) isolates from southern African maize. Food Cosmet. Toxicol. 19:447-456.

Kvas, M., Marasas, W. F. O., Wingfield, B. D., Wingfield, M. J., and Steenkamp, E. T. 2009. Diversity and evolution of Fusarium species in the Gibberella fujikuroi complex. Fungal Divers. 34:1-21.

Lan, N., Zhang, H., Hu, C., Wang, W., Calvo, A. M., Harris, S. D., Chen, S., and $\mathrm{Li}$, S. 2014. Coordinated and distinct functions of velvet proteins in Fusarium verticillioides. Eukaryot. Cell 13:909-918.

Laurent, D., Lanson, M., Goasdoue, N., Kohler, F., Pellegrin, F., and Platzer, N. 1990. Etude en RMN 1H et 13C de la macrofusine, toxine isolée de mais infesté par Fusarium moniliforme Sheld. Analusis 18:I72-I79.
Laurent, D., Platzer, N., Kohler, F., Sauviat, M., and Pellegrin, F. 1989. Macrofusine et micromoniline: Deux nouvelles mycotoxines isolées de mais infesté par Fusarium moniliforme Sheld. Microbiol. Aliments Nutr. 7: 9-16.

Leslie, J. F., and Summerell, B. A., eds. 2006. The Fusarium Laboratory Manual. Blackwell Publishing, Ames, IA.

Leslie, J. F., and Summerell, B. A. 2013. An overview of Fusarium. Pages 1-9 in: Fusarium: Genomics, Molecular and Cellular Biology. D. W. Brown and R. H. Proctor, eds. Caister Academic Press, Norfolk, UK.

Li, S., Myung, K., Guse, D., Donkin, B., Proctor, R. H., Grayburn, W. S., and Calvo, A. M. 2006. FvVE1 regulates filamentous growth, the ratio of microconidia to macroconidia and cell wall formation in Fusarium verticillioides. Mol. Microbiol. 62:1418-1432.

Liu, H., Lu, Y., Haynes, J. S., Cunnick, J. E., Murphy, P., and Hendrich, S. 2001. Reaction of fumonisin with glucose prevents promotion of hepatocarcinogenesis in female F344/N rats while maintaining normal hepatic sphinganine/sphingosine ratios. J. Agric. Food Chem. 49:4113-4121.

Malapi-Wight, M., Kim, J. E., and Shim, W. B. 2014. The N-terminus region of the putative $\mathrm{C}_{2} \mathrm{H}_{2}$ transcription factor Ada1 harbors a species-specific activation motif that regulates asexual reproduction in Fusarium verticillioides. Fungal Genet. Biol. 62:25-33.

Månsson, M., Klejnstrup, M. L., Phipps, R. K., Nielsen, K. F., Frisvad, J. C., Gotfredsen, C. H., and Larsen, T. O. 2010. Isolation and NMR characterization of fumonisin $\mathrm{B}_{2}$ and a new fumonisin $\mathrm{B}_{6}$ from Aspergillus niger. $\mathrm{J}$. Agric. Food Chem. 58:949-953.

Marasas, W. 2001. Discovery and occurrence of the fumonisins: A historical perspective. Environ. Health Perspect. 109:239-243.

Marasas, W., Kellerman, T., Pienaar, J., and Naude, T. 1976. Leukoencephalomalacia: A mycotoxicosis of Equidae caused by Fusarium moniliforme Sheldon. Onderstepoort J. Vet. Res. 43:113-122.

Marasas, W. F., Kriek, N. P., Fincham, J. E., and Van Rensburg, S. J. 1984. Primary liver cancer and oesophageal basal cell hyperplasia in rats caused by Fusarium moniliforme. Int. J. Cancer 34:383-387.

Maschietto, V., Lanubile, A., Leonardis, S. D., Marocco, A., and Paciolla, C. 2016. Constitutive expression of pathogenesis-related proteins and antioxydant enzyme activities triggers maize resistance towards Fusarium verticillioides. J. Plant Physiol. 200:53-61.

May, G., and Nelson, P. 2014. Defensive mutualisms: Do microbial interactions within hosts drive the evolution of defensive traits? Funct. Ecol. 28: 356-363.

Michaelson, L. V., Napier, J. A., Molino, D., and Faure, J.-D. 2016. Plant sphingolipids: Their importance in cellular organization and adaption. BBA-Mol. Cell Biol. Lipids 1861:1329-1335.

Mukherjee, M., Kim, J.-E., Park, Y.-S., Kolomiets, M. V., and Shim, W.-B. 2011. Regulators of G-protein signalling in Fusarium verticillioides mediate differential host-pathogen responses on nonviable versus viable maize kernels. Mol. Plant Pathol. 12:479-491.

Munkvold, G. P. 2003a. Epidemiology of Fusarium diseases and their mycotoxins in maize ears. Eur. J. Plant Pathol. 109:705-713.

Munkvold, G. P. 2003b. Cultural and genetic approaches to managing mycotoxins in maize. Annu. Rev. Phytopathol. 41:99-116.

Munkvold, G. P., Hellmich, R. L., and Showers, W. B. 1997. Reduced fusarium ear rot and symptomless infection in kernels of maize genetically engineered for European corn borer resistance. Phytopathology 87:1071-1077.

Murillo, I., Cavallarin, L., and Segundo, B. S. 1999. Cytology of infection of maize seedlings by Fusarium moniliforme and immunolocalization of the pathogenesis-related PRms protein. Phytopathology 89:737-747.

Naumann, T. A., Wicklow, D. T., and Price, N. P. J. 2011. Identification of a chitinase-modifying protein from Fusarium verticillioides: Truncation of a host resistance protein by a fungalysin metalloprotease. J. Biol. Chem. 286: 35358-35366

Nguyen, T. T. X., Dehne, H.-W., and Steiner, U. 2016a. Histopathological assessment of the infection of maize leaves by Fusarium graminearum, F. proliferatum, and F. verticillioides. Fungal Biol. 120:1094-1104.

Nguyen, T. T. X., Dehne, H.-W., and Steiner, U. 2016b. Maize leaf trichomes represent an entry point of infection for Fusarium species. Fungal Biol. 120: 895-903.

Niemeyer, H. M. 2009. Hydroxamic acids derived from 2-hydroxy-2H-1,4benzoxazin-3(4H)-one: Key defense chemicals of cereals. J. Agric. Food Chem. 57:1677-1696.

Niu, C., Payne, G. A., and Woloshuk, C. P. 2015. Transcriptome changes in Fusarium verticillioides caused by mutation in the transporter-like gene FST1. BMC Microbiol. 15:90.

O’Donnell, K., Nirenberg, H. I., Aoki, T., and Cigelnik, E. 2000. A multigene phylogeny of the Gibberella fujikuroi species complex: Detection of additional phylogenetically distinct species. Mycoscience 41:61-78.

O’Donnell, K., Rooney, A. P., Proctor, R. H., Brown, D. W., McCormick, S. P., Ward, T. J., Frandsen, R. J. N., Lysøe, E., Rehner, S. A., Aoki, T., Robert, 
V. A. R. G., Crous, P. W., Groenewald, J. Z., Kang, S., and Geiser, D. M. 2013. Phylogenetic analyses of $R P B 1$ and $R P B 2$ support a middle Cretaceous origin for a clade comprising all agriculturally and medically important fusaria. Fungal Genet. Biol. 52:20-31.

Oh, M., Son, H., Choi, G. J., Lee, C., Kim, J.-C., Kim, H., and Lee, Y.-W. 2016. Transcription factor ART1 mediates starch hydrolysis and mycotoxin production in Fusarium graminearum and $F$. verticillioides. Mol. Plant Pathol. 17:755-768.

Oren, L., Ezrati, S., Cohen, D., and Sharon, A. 2003. Early events in the Fusarium verticillioides-maize interaction characterized by using a green fluorescent protein-expressing transgenic isolate. Appl. Environ. Microbiol. 69:1695-1701.

Ortiz, C. S., and Shim, W.-B. 2013. The role of MADS-box transcription factors in secondary metabolism and sexual development in the maize pathogen Fusarium verticillioides. Microbiology 159:2259-2268.

Ostry, V., Malir, F., Toman, J., and Grosse, Y. 2017. Mycotoxins as human carcinogens-The IARC Monographs classification. Mycotoxin Res. 33: 65-73.

Pamphile, J. A., and Azevedo, J. L. 2002. Molecular characterization of endophytic strains of Fusarium verticillioides ( $=$ Fusarium moniliforme) from maize (Zea mays. L). World J. Microbiol. Biotechnol. 18:391-396.

Parsons, M. W., and Munkvold, G. P. 2010. Relationships of immature and adult thrips with silk-cut, fusarium ear rot and fumonisin B1 contamination of maize in California and Hawaii. Plant Pathol. 59:1099-1106.

Parsons, M. W., and Munkvold, G. P. 2012. Effects of planting date and environmental factors on fusarium ear rot symptoms and fumonisin B1 accumulation in maize grown in six North American locations. Plant Pathol. 61:1130-1142.

Pelizza, S. A., Stenglein, S. A., Cabello, M. N., Dinolfo, M. I., and Lange, C. E. 2011. First record of Fusarium verticillioides as an entomopathogenic fungus of grasshoppers. J. Insect Sci. 11:70.

Pereira, P., Nesci, A., Castillo, C., and Etcheverry, M. 2010. Impact of bacterial biological control agents on fumonisin B1 content and Fusarium verticillioides infection of field-grown maize. Biol. Control 53:258-266.

Pereira, P., Nesci, A., and Etcheverry, M. 2007. Effects of biocontrol agents on Fusarium verticillioides count and fumonisin content in the maize agroecosystem: Impact on rhizospheric bacterial and fungal groups. Biol. Control 42:281-287.

Picot, A., Barreau, C., Pinson-Gadais, L., Caron, D., Lannou, C., and Richard-Forget, F. 2010. Factors of the Fusarium verticillioides-maize environment modulating fumonisin production. Crit. Rev. Microbiol. 36:221-231.

Pomraning, K. R., Connolly, L. R., Whalen, J. P., Smith, K. M., and Freitag, M. 2013. Repeat-induced point mutation, DNA methylation and heterochromatin in Gibberella zeae (anamorph: Fusarium graminearum). Pages 93-109 in: Fusarium: Genomics, Molecular and Cellular Biology. D. W. Brown and R. H. Proctor, eds. Caister Academic Press, Norfolk, UK.

Probst, C., Njapau, H., and Cotty, P. J. 2007. Outbreak of an acute aflatoxicosis in Kenya in 2004: Identification of the causal agent. Appl. Environ. Microbiol. 73:2762-2764.

Proctor, R. H., Busman, M., Seo, J.-A., Lee, Y. W., and Plattner, R. D. 2008. A fumonisin biosynthetic gene cluster in Fusarium oxysporum strain O-1890 and the genetic basis for B versus C fumonisin production. Fungal Genet. Biol. 45:1016-1026.

Proctor, R. H., Van Hove, F., Susca, A., Stea, G., Busman, M., van der Lee, T., Waalwijk, C., Moretti, A., and Ward, T. J. 2013. Birth, death and horizontal transfer of the fumonisin biosynthetic gene cluster during the evolutionary diversification of Fusarium. Mol. Microbiol. 90:290-306.

Ramamoorthy, V., Govindaraj, L., Dhanasekaran, M., Vetrivel, S., Kumar, K. K., and Ebenezar, E. 2015. Combination of driselase and lysing enzyme in one molar potassium chloride is effective for the production of protoplasts from germinated conidia of Fusarium verticillioides. J. Microbiol. Methods 111:127-134.

Ravalason, H., Grisel, S., Chevret, D., Favel, A., Berrin, J.-G., Sigoillot, J.-C., and Herpoël-Gimbert, I. 2012. Fusarium verticillioides secretome as a source of auxiliary enzymes to enhance saccharification of wheat straw. Bioresour. Technol. 114:589-596.

Ridenour, J. B., and Bluhm, B. H. 2014. The HAP complex in Fusarium verticillioides is a key regulator of growth, morphogenesis, secondary metabolism, and pathogenesis. Fungal Genet. Biol. 69:52-64.

Ridenour, J. B., and Bluhm, B. H. 2017. The novel fungal-specific gene FUG1 has a role in pathogenicity and fumonisin biosynthesis in Fusarium verticillioides. Mol. Plant Pathol. 18:513-528.

Ridenour, J. B., Smith, J. E., Hirsch, R. L., Horevaj, P., Kim, H., Sharma, S., and Bluhm, B. H. 2014. UBL1 of Fusarium verticillioides links the N-end rule pathway to extracellular sensing and plant pathogenesis. Environ. Microbiol. 16:2004-2022.

Riley, R. T., Enongene, E., Voss, K. A., Norred, W. P., Meredith, F. I., Sharma, R. P., Spitsbergen, J., Williams, D. E., Carlson, D. B., and Merrill, A. H., Jr.
2001. Sphingolipid perturbations as mechanisms for fumonisin carcinogenesis. Environ. Health Perspect. 109:301-308.

Riley, R. T., Showker, J. L., Lee, C. M., Zipperer, C. E., Mitchell, T. R., Voss, K. A., Zitomer, N. C., Torres, O., Matute, J., and Gregory, S. G. 2015. A blood spot method for detecting fumonisin-induced changes in putative sphingolipid biomarkers in $\mathrm{LM} / \mathrm{Bc}$ mice and humans. Food Addit. Contam. Part A 32:934-949.

Rossi, V., Scandolara, A., and Battilani, P. 2009. Effect of environmental conditions on spore production by Fusarium verticillioides, the causal agent of maize ear rot. Eur. J. Plant Pathol. 123:159-169.

Sagaram, U. S., Butchko, R. A. E., and Shim, W.-B. 2006. The putative monomeric G-protein $G B P 1$ is negatively associated with fumonisin $\mathrm{B}_{1}$ production in Fusarium verticillioides. Mol. Plant Pathol. 7:381-389.

Sagaram, U. S., and Shim, W.-B. 2007. Fusarium verticillioides GBB1, a gene encoding heterotrimeric $G$ protein $\beta$ subunit, is associated with fumonisin $B_{1}$ biosynthesis and hyphal development but not with fungal virulence. Mol. Plant Pathol. 8:375-384.

Sánchez-Rangel, D., and Plasencia, J. 2010. The role of sphinganine analog mycotoxins on the virulence of plant pathogenic fungi. Toxin Rev. 29: 73-86.

Sánchez-Rangel, D., Sanchez-Nieto, S., and Plasencia, J. 2012. Fumonisin B1, a toxin produced by Fusarium verticillioides, modulates maize beta1,3-glucanase activities involved in defense response. Planta 235:965-978.

Saunders, M., Glenn, A. E., and Kohn, L. M. 2010. Exploring the evolutionary ecology of fungal endophytes in agricultural systems: Using functional traits to reveal mechanisms in community processes. Evol. Appl. 3: 525-537.

Saunders, M., and Kohn, L. M. 2009. Evidence for alteration of fungal endophyte community assembly by host defense compounds. New Phytol. 182:229-238.

Scala, V., Beccaccioli, M., Dall'Asta, C., Giorni, P., and Fanelli, C. 2015. Analysis of the expression of genes related to oxylipin biosynthesis in Fusarium verticillioides and maize kernels during their interaction. J. Plant Pathol. 97:193-197.

Scala, V., Giorni, P., Cirlini, M., Ludovici, M., Visentin, I., Cardinale, F., Fabbri, A. A., Fanelli, C., Reverberi, M., Battilani, P., Galaverna, G., and Dall'Asta, C. 2014. LDS1-produced oxylipins are negative regulators of growth, conidiation and fumonisin synthesis in the fungal maize pathogen Fusarium verticillioides. Front. Microbiol. 5:669.

Schulz, B., and Boyle, C. 2005. The endophytic continuum. Mycol. Res. 109: 661-686.

Shim, W.-B., Flaherty, J. E., and Woloshuk, C. P. 2003. Comparison of fumonisin B1 biosynthesis in maize germ and degermed kernels by Fusarium verticillioides. J. Food Prot. 66:2116-2122.

Shim, W.-B., Sagaram, U. S., Choi, Y.-E., So, J., Wilkinson, H. H., and Lee, Y. W. 2006. FSR1 is essential for virulence and female fertility in Fusarium verticillioides and F. graminearum. Mol. Plant-Microbe Interact. 19:725-733.

Shirima, C. P., Kimanya, M. E., Routledge, M. N., Srey, C., Kinabo, J. L., Humpf, H.-U., Wild, C. P., Tu, Y.-K., and Gong, Y. Y. 2015. A prospective study of growth and biomarkers of exposure to aflatoxin and fumonisin during early childhood in Tanzania. Environ. Health Perspect. 123:173-178.

Skoglund, L., and Brown, W. 1988. Effects of tillage regimes and herbicides on Fusarium species associated with corn stalk rot. Can. J. Plant Pathol. 10: 332-338.

Slavokhotova, A. A., Naumann, T. A., Price, N. P., Rogozhin, E. A., Andreev, Y. A., Vassilevski, A. A., and Odintsova, T. I. 2014. Novel mode of action of plant defense peptides-Hevein-like antimicrobial peptides from wheat inhibit fungal metalloproteases. FEBS J. 281:4754-4764.

Sobek, E. A., and Munkvold, G. P. 1999. European Corn Borer (Lepidoptera: Pyralidae) larvae as vectors of Fusarium moniliforme, causing kernel rot and symptomless infection of maize kernels. J. Econ. Entomol. 92:503-509.

Sperschneider, J., Gardiner, D. M., Thatcher, L. F., Lyons, R., Singh, K. B., Manners, J. M., and Taylor, J. M. 2015. Genome-wide analysis in three Fusarium pathogens identifies rapidly evolving chromosomes and genes associated with pathogenicity. Genome Biol. Evol. 7:1613-1627.

Stajich, J. E., Harris, T., Brunk, B. P., Brestelli, J., Fischer, S., Harb, O. S., Kissinger, J. C., Li, W., Nayak, V., Pinney, D. F., Stoeckert, C. J., Jr., and Roos, D. S. 2012. FungiDB: An integrated functional genomics database for fungi. Nucleic Acids Res. 40:D675-D681.

Tamura, M., Mochizuki, N., Nagatomi, Y., Harayama, K., Toriba, A., and Hayakawa, K. 2015. Identification and quantification of fumonisin A1, A2, and $\mathrm{A} 3$ in corn by high-resolution liquid chromatography-orbitrap mass spectrometry. Toxins (Basel) 7:582-592.

Tipper, D. J. 1985. Mode of action of $\beta$-lactam antibiotics. Pharmacol. Ther. 27:1-35.

VanEtten, H. D., Mansfield, J. W., Bailey, J. A., and Farmer, E. E. 1994. Two classes of plant antibiotics: Phytoalexins versus "phytoanticipins". Plant Cell 6:1191-1192. 
Van Hove, F., Waalwijk, C., Logrieco, A., Munaut, F., and Moretti, A. 2011. Gibberella musae (Fusarium musae) sp. nov., a recently discovered species from banana is sister to $F$. verticillioides. Mycologia 103:570-585.

Vilich, V., Lohndorf, B., Sikora, R. A., and Friebe, A. 1999. Metabolism of benzoxazolinone allelochemicals of Zea mays by Fusarium subglutinans. Mycol. Res. 103:1529-1532.

Visentin, I., Montis, V., Döll, K., Alabouvette, C., Tamietti, G., Karlovsky, P., and Cardinale, F. 2012. Transcription of genes in the biosynthetic pathway for fumonisin mycotoxins is epigenetically and differentially regulated in the fungal maize pathogen Fusarium verticillioides. Eukaryot. Cell 11:252-259.

Voss, K. A., Chamberlain, W. J., Bacon, C. W., Herbert, R. A., Walters, D. B., and Norred, W. P. 1995. Subchronic feeding study of the mycotoxin fumonisin B1 in B6C3F1 mice and Fischer 344 rats. Toxicol. Sci. 24:102-110.

Voss, K. A., Chamberlain, W. J., Bacon, C. W., and Norred, W. P. 1993. A preliminary investigation on renal and hepatic toxicity in rats fed purified fumonisin B1. Nat. Toxins 1:222-228.

Voss, K. A., Norred, W. P., Plattner, R. D., and Bacon, C. W. 1989. Hepatotoxicity and renal toxicity in rats of corn samples associated with field cases of equine leukoencephalomalacia. Food Chem. Toxicol. 27:89-96.

Voss, K. A., Riley, R. T., Jackson, L. S., Jablonski, J. E., Bianchini, A., Bullerman, L. B., Hanna, M. A., and Ryu, D. 2011. Extrusion cooking with glucose supplementation of fumonisin-contaminated corn grits protects against nephrotoxicity and disrupted sphingolipid metabolism in rats. Mol. Nutr. Food Res. 55:S312-S320.

Voss, K. A., Riley, R. T., Moore, N. D., and Burns, T. D. 2013. Alkaline cooking (nixtamalisation) and the reduction in the in vivo toxicity of fumonisin-contaminated corn in a rat feeding bioassay. Food Addit. Contam. Part A 30:1415-1421.

Voss, K. A., Riley, R. T., Snook, M. E., and Gelineau-van Waes, J. 2009. Reproductive and sphingolipid metabolic effects of fumonisin B1 and its alkaline hydrolysis product in $\mathrm{LM} / \mathrm{Bc}$ mice: Hydrolyzed fumonisin B1 did not cause neural tube defects. Toxicol. Sci. 112:459-467.

Voss, K. A., Smith, G. W., and Haschek, W. M. 2007. Review: Fumonisins: Toxicokinetics, mechanism of action and toxicity. Anim. Feed Sci. Technol. 137:299-325.

Wang, E., Norred, W., Bacon, C., Riley, R., and Merrill, A. H. 1991. Inhibition of sphingolipid biosynthesis by fumonisins. Implications for diseases associated with Fusarium moniliforme. J. Biol. Chem. 266:14486-14490.

Wiemann, P., Sieber, C. M., von Bargen, K. W., Studt, L., Niehaus, E. M., Espino, J. J., Huss, K., Michielse, C. B., Albermann, S., Wagner, D.,
Bergner, S. V., Connolly, L. R., Fischer, A., Reuter, G., Kleigrewe, K., Bald, T., Wingfield, B. D., Ophir, R., Freeman, S., Hippler, M., Smith, K. M., Brown, D. W., Proctor, R. H., Munsterkotter, M., Freitag, M., Humpf, H. U., Guldener, U., and Tudzynski, B. 2013. Deciphering the cryptic genome: Genome-wide analyses of the rice pathogen Fusarium fujikuroi reveal complex regulation of secondary metabolism and novel metabolites. PLoS Pathog. 9:e1003475.

Williams, L. D., Glenn, A. E., Zimeri, A. M., Bacon, C. W., Smith, M. A., and Riley, R. T. 2007. Fumonisin disruption of ceramide biosynthesis in maize roots and the effects on plant development and Fusarium verticillioidesinduced seedling disease. J. Agric. Food Chem. 55:2937-2946.

Wilson, T. M., Nelson, P. E., and Knepp, C. 1985. Hepatic neoplastic nodules, adenofibrosis, and cholangiocarcinomas in male Fisher 344 rats fed corn naturally contaminated with Fusarium moniliforme. Carcinogenesis 6: 1155-1160.

Woloshuk, C. P., and Shim, W.-B. 2013. Aflatoxins, fumonisins, and trichothecenes: A convergence of knowledge. FEMS Microbiol. Rev. 37:94-109.

Wright, S. I., Bi, I. V., Schroeder, S. G., Yamasaki, M., Doebley, J. F., McMullen, M. D., and Gaut, B. S. 2005. The effects of artificial selection on the maize genome. Science 308:1310-1314

Wu, F. 2006. Mycotoxin reduction in Bt corn: Potential economic, health, and regulatory impacts. Transgenic Res. 15:277-289.

Xu, J., Yan, K., Dickman, M., and Leslie, J. 1995. Electrophoretic karyotypes distinguish the biological species of Gibberella fujikuroi (Fusarium section Liseola). Mol. Plant-Microbe Interact. 8:74-84.

Yates, I. E., Bacon, C. W., and Hinton, D. M. 1997. Effects of endophytic infection by Fusarium moniliforme on corn growth and cellular morphology. Plant Dis. 81:723-728.

Zhang, C., Wang, J., Tao, H., Dang, X., Wang, Y., Chen, M., Zhai, Z., Yu, W., Xu, L., Shim, W.-B., and Lu, G. 2015. FvBck1, a component of cell wall integrity MAP kinase pathway, is required for virulence and oxidative stress response in sugarcane Pokkah Boeng pathogen. Front. Microbiol. 6:1096.

Zhang, Y., Choi, Y.-E., Zou, X., and Xu, J.-R. 2011. The FvMK1 mitogenactivated protein kinase gene regulates conidiation, pathogenesis, and fumonisin production in Fusarium verticillioides. Fungal Genet. Biol. 48: 71-79.

Zitomer, N. C., Jones, S., Bacon, C., Glenn, A. E., Baldwin, T., and Riley, R. T. 2010. Translocation of sphingoid bases and their 1-phosphates, but not fumonisins, from roots to aerial tissues of maize seedlings watered with fumonisins. J. Agric. Food Chem. 58:7476-7481. 